\title{
Evaluation of Dark Etching Regions for Standard Bearing Steel under Accelerated Rolling Contact Fatigue
}

\author{
Muhammad U Abdullah ${ }^{\mathrm{a}}$, Zulfiqar A Khan ${ }^{\mathrm{a}^{*}}$, Wolfram Kruhoeffer ${ }^{\mathrm{b}}$, \\ aBournemouth University, Department of Design \& Engineering, NanoCorr, Energy \& Modelling \\ (NCEM) Research Group, Poole, Dorset, United Kingdom \\ ${ }^{\mathrm{b}}$ Schaeffler Technologies AG \& Co. KG, Herzogenaurach, Germany
}

\begin{abstract}
Subsurface microstructural alterations are formed in the later stages of rolling contact fatigue (RCF) under high contact pressure. The subsurface changes observed as a dark contrast under optical microscopy are classified as Dark Etching Regions (DERs). Despite the fact that DERs have been presented for several decades, the understanding of its development and growth is yet to comprehend. Current research employed a modified high-speed microprocessor rotary tribometer to conduct systematic RCF study under accelerated testing conditions with variable temperatures and contact pressures. Comprehensive RCF data has been acquired, analysed and is reported for the very first time with ball-on-ball point contact loading conditions. The subsurface microscopic investigations have shown the ongoing progression and development of DER extent and are reported to be associated with the accumulation of plasticity during RCF. The comparison of the DER with the responsible stress components have revealed that DER formation is more closely related to the von Mises stresses when superposed with residual stresses. The experimentally observed area fraction of dark etching zones has been evaluated in terms of DER\% and compared with the dislocation assisted carbon diffusion model for DER formation. The overprediction of the numerical model in comparison with the presented results in current research manifests its limitations which can be improved with the incorporation of cyclic plasticity governed by evolved von Mises stresses. The evaluated DER results are further presented as a 3D DER\% maps incorporating the combined effects of contact stress, temperature and rolling cycles simultaneously which provides a comprehensive understanding of RCF from a microstructural point of view and thus can be used as guidelines for DER formation models.
\end{abstract}

Keywords: Ball Bearings, Rolling Contact Fatigue, Dark Etching Regions, White Etching Bands, 4Ball Test

\section{Introduction}

Bearing elements during service are exposed to cyclic loadings resulting in rolling contact fatigue (RCF). Carbides volume fraction, retained austenite, microtexture, microstructure and non-metallic inclusions create complexities in the bearing material microstructure which evolves over millions of stress cycles during non-proportional stress histories [1]. A typical microstructure of an AISI 52100 bearing steel consists of parent martensite, primary carbides and 6-11\% remaining austenite. It is well known that the cyclic stressing at sufficiently high contact pressure change the bearing material microstructure and this altered microstructure can be seen as dark/white contrast under optical microscopy (OM) after Nital etching. These black patches observed with OM make it distinct from the original parent martensitic needle-like structure and are termed as Dark Etching Regions (DER) [2, 3]. It was reported [3] that the formation of DER is associated with the maximum orthogonal shear stress and cannot be formed below a certain threshold of corresponding stress level. Moreover, it was reported 
that the formation of DER is also related to the subsequent softening of RCF stressed zone below the contact track $[4,5]$.

The structural evolution of bearing steel during RCF causes phase transformation during which retained austenite transforms and decay of martensite takes place [6]. DER is manifested as decay of martensite after plastic shakedown and is believed to be a tempered form of martensite. DER is characterised as an increase in the area fraction of dark patches under the stressed zone of RCF loading [7]. Earlier studies have shown $[3,8]$ that the DER microstructure is a mixture of ferrite phase and deformed martensite where the excess carbon in the martensite matrix is reprecipitated within DER ferrite. Kang et al. [9] postulated that excess carbon during martensite-ferrite phase transformation diffuse to the preexisting carbides and causes the carbide thickening in the DER matrix. A recent study [4] has conducted the atomic probe tomography of DER region and showed recrystallisation of carbides in DER region. Based on this carbon diffusion theory, Pernach [10] presented a numerical model of carbon diffusion within austenite-ferrite phase transformation. This model was extended by Warhadpande et al. [11] where the diffusion equations were coupled with elastic-plastic Hertzian contact theory and stress assisted diffusion equation was presented which describes the carbon diffusion out of the martensite matrix during cyclic loading. Mitamura [12] after RCF testing of tempered bearing balls samples proposed that the structural alterations are controlled by the thermal diffusion of carbon in ferrite matrix which results in precipitation of excess carbon along with pre-existing primary carbides. The amount of carbon that contributes to carbide thickening can be computed by taking into account its thermal diffusion and the binding energy with the carbide. This kinetics of carbide thickening was predicted by Kang et al. [9] via dislocation-assisted diffusivity and Fick's law of diffusion. Fu et al. [4] suggested that the martensite decay during RCF is manifested as DER formation and can be described by dislocation gliding mechanism. Nevertheless, all these studies are focused on the carbon migration in ferrite matrix which can be controlled by either thermal diffusion or gliding dislocations.

Current research work aims to quantify the microstructural alterations (DERs in particular) in a systematic way and create a ground understanding of their formation mechanism. Series of tests have been conducted on a standard AISI 52100 bearing balls under three different contact pressures (4GPa, $5 \mathrm{GPa}$ and $6 \mathrm{GPa})$ and operating temperatures $\left(40^{\circ} \mathrm{C}, 100^{\circ} \mathrm{C}\right.$ and $\left.160^{\circ} \mathrm{C}\right)$. Such extreme contact pressures are rarely met in practice except for quasi-static rolling bearings and the temperature as high as $160^{\circ} \mathrm{C}$ is quite close to the tempering temperature of bearing steel. The purpose of selecting such extreme testing conditions is to accelerate the microstructural phenomenon and carry out the study in a feasible duration. After RCF test, subsurface has been investigated for visible dark etching regions and presented in terms of area fraction of DER. This area fraction of dark regions with relatives to the parent martensitic matrix is termed as DER\%. The acquired DER\% results are presented in form of a useful tool as a 3D DER\% map with temperature and pressure variation. Finally, the reported data has also been compared with the gliding dislocation model for DER formation.

\section{Experimental Details}

\subsection{Material}

The material investigated in all RCF experimentation ( $12.7 \mathrm{~mm}$ ball diameter) is standard AISI 52100 bearing steel (also known as 100Cr6) which was subjected to martensitic hardening. The standard chemical composition is listed in Table 1 . The subsurface hardness as investigated from a virgin material showed a hardness range of $820 \pm 30$ HV0.3.

It should be noted that the bearing balls used in this study were not tumbled during manufacturing. Early studies $[6,13]$ have shown close proximity of subsurface residual stresses with microstructural 
alterations, hence use of untumbled balls in the current study would simplify the case by avoiding manufacturing induced residual stresses.

Table 1. Chemical composition of standard AISI-52100 bearing steel (values in \%wt)

\begin{tabular}{ccccccc}
\hline $\mathrm{C}$ & $\mathrm{Cr}$ & $\mathrm{Si}$ & $\mathrm{Cu}$ & $\mathrm{Mn}$ & $\mathrm{Al}$ & $\begin{array}{c}\text { Other } \\
\text { elements }\end{array}$ \\
$0.9-1.05 \%$ & $1.35-1.60 \%$ & $0.15-0.35 \%$ & $0.01 \%$ & $0.25-0.45 \%$ & $0.01 \%$ & $<0.01 \%$ \\
\hline
\end{tabular}

\subsection{Testing}

RCF experimentation was conducted in a PLINT rotary tribometer TE-92 with 4-ball configuration (figure 1) where three lower balls are kept (free to roll) in a cup which works like an outer race of a bearing. The tested ball is the upper ball. It is mounted on a shaft with a collet and rotates on top of lower three balls forming a contact track similar to the contact track of the inner ring of a bearing [14]. As per Kruger \& Blitz equation [15], one complete revolution of the upper ball having same diameter as the lower three balls results in 2.25 stress cycles.

A series of tests were conducted at a spindle speed of $4051 \mathrm{rpm}$ (resulted in $4051 * 2.25=9115$ stress cycles $/ \mathrm{min}$ ) with three operating temperatures $\left(40^{\circ} \mathrm{C}, 100^{\circ} \mathrm{C}\right.$ and $160^{\circ} \mathrm{C}$ ) and three load levels (resulting in $6 \mathrm{GPa}, 5 \mathrm{GPa}$ and $4 \mathrm{GPa}$ maximum Hertzian contact pressure). The temperature was monitored continuously by a K-type thermocouple installed in the cup housing and was kept constant before each test to normalise the testing conditions. Each test was either stopped after a defined number of stress cycles or whenever the sample fails due to spalling, detected by a vibration cut-off sensor. Complete experimentation list is available in Table 2.

A PAO base oil ISO-VG-320 with a kinematic viscosity of $300 \mathrm{cst}\left(\right.$ at $40^{\circ} \mathrm{C}$ ) was used as a lubricant such that the 4-ball test can run with minimal to no asperity interaction and pure subsurface microstructural alterations can be evaluated. The minimum film thickness and specific film thickness have been calculated for extreme testing conditions and is shown in Appendix.

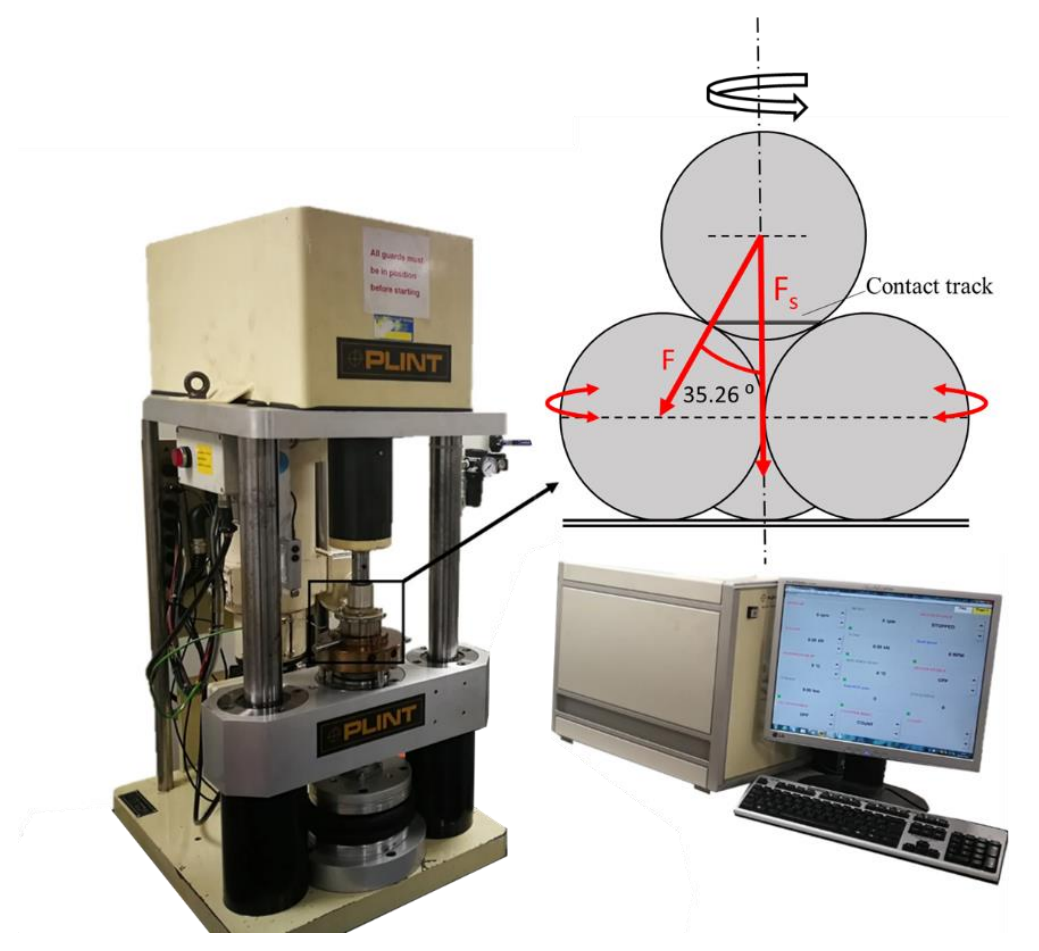


Figure 1. 4-ball tester, Fs represents axial shaft load and F represents the resultant load

Table 2. Four-ball experiments conducted for subsurface RCF investigation

\begin{tabular}{cccc}
\hline $\begin{array}{c}\text { Shaft load } \\
\left(\mathrm{F}_{\mathrm{s}}\right)\end{array}$ & $\begin{array}{c}\text { Maximum contact stress } \\
(\mathrm{GPa})\end{array}$ & $\begin{array}{c}\text { Temperature } \\
\left({ }^{\circ} \mathrm{C}\right)\end{array}$ & $\begin{array}{c}\text { Stress cycles } \\
\text { (in Million) }\end{array}$ \\
\hline \multirow{2}{*}{2100} & \multirow{2}{*}{6} & $40^{\circ} \mathrm{C}$ & $5,11,42$ \\
& & $100^{\circ} \mathrm{C}$ & $1,5,11,22,37$ \\
& 5 & $160^{\circ} \mathrm{C}$ & $1,5,11,22,37$ \\
1200 & 5 & $40^{\circ} \mathrm{C}$ & 37 \\
& & $100^{\circ} \mathrm{C}$ & $5,11,22,37$ \\
650 & 4 & $460^{\circ} \mathrm{C}$ & $5,11,22,37$ \\
& & $40^{\circ} \mathrm{C}$ & $37 \times 10^{6}$ \\
& & $100^{\circ} \mathrm{C}$ & $5,11,37$ \\
& & & \\
\hline
\end{tabular}

The contact track formed after over rolling can be seen as a ring track on the upper ball and was examined with the help of an optical interferometer during RCF testing. After the test, the upper ball was sliced with a precision cutter in a circumferential and axial direction, as shown in figure 2 . After slicing, the samples were cold mounted and then polished with diamond suspension of $9 \mu \mathrm{m}$ and then $3 \mu \mathrm{m}$ particle size to achieve a mirror-like surface. Samples were then etched with $3 \%$ Nital $(97 \%$ Ethanol, 3\% Nitric acid) by dipping in solution. It was noted that the sample grain boundaries can be revealed for a freshly cut sample during 3-5 sec of etching time. The controlled etching time and repeated etching process created uniformity during microscopic analysis.

(a)

(b)

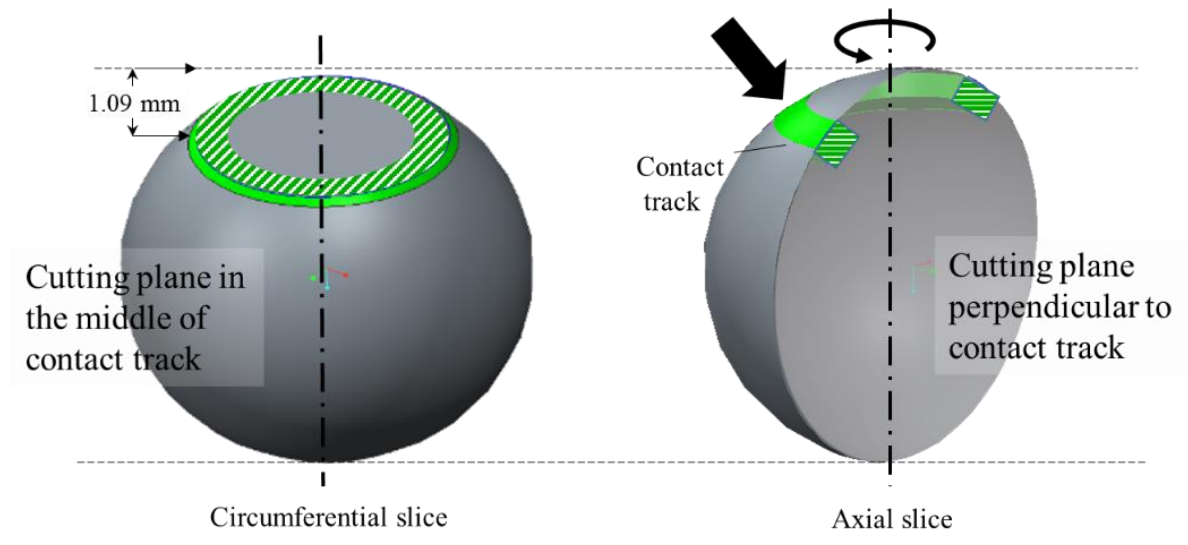

Figure 2. Cross-section views for RCF tested upper ball (a) represents circumferential slice cut in the middle of contact track at a distance $1.09 \mathrm{~mm}$ from top (b) represents axial slice revealing contact track at two points

\section{DER Evaluation (DER\%)}

The continuously changing stress histories and unique subsurface deformation during each rolling cycle make the RCF distinct from the uniaxial fatigue. The resulting dislocations during RCF deformations are not limited to move in one direction but they can repeatedly change their orientations. Such dislocation motions make the possibilities that the dislocations can interact with the number of solute items and particles. Moreover, the carbon segregation during cyclic loading can be controlled by concentration gradients, diffusivity and extent of dislocation motion created during RCF [16]. The visibility of dark patches in the parent martensite after Nital etching indicates the precipitation of excess carbon, given that Nital attacks carbide-ferrite interfaces. As explained in section 1, the development of 
these dark patches with respect to the number of cycles is demonstrated as an increase in the area fraction of DER and can be expressed as DER\% [4].

$$
\text { DER\% }=(\text { Area fraction of black patches in DER zone }) * 100
$$

However, this DER\% evaluation (dark patches area) depends on extent of etching and image contrast during bright field microscopy. It should be noted that the over-etched sample in the metallography process creates a higher contrast of the decayed martensite as compared with a nominal etched surface. It is quite impossible to etch all the metallographic samples under same conditions as etching of surface depends upon several factors which are quite difficult to control and unify for each sample.

In order to address these issues during DER\% evaluation, a Matlab programme was developed to quantify the DER\% which represents the averaged value in each layer of pixels and is shown in figure 3. The microscopy image obtained from a polished and etched sample which was initially converted to an 8-bit binary image which was then read by the code to calculate the black bits from white bits and generated the precise measurement of area fraction of back patches along with depth distribution. The relative difference of the measured value of DER with reference to the parent martensitic baseline, yielded the actual DER\% which was then applied to all the samples and provided a unified method for calculating

DER percentages.

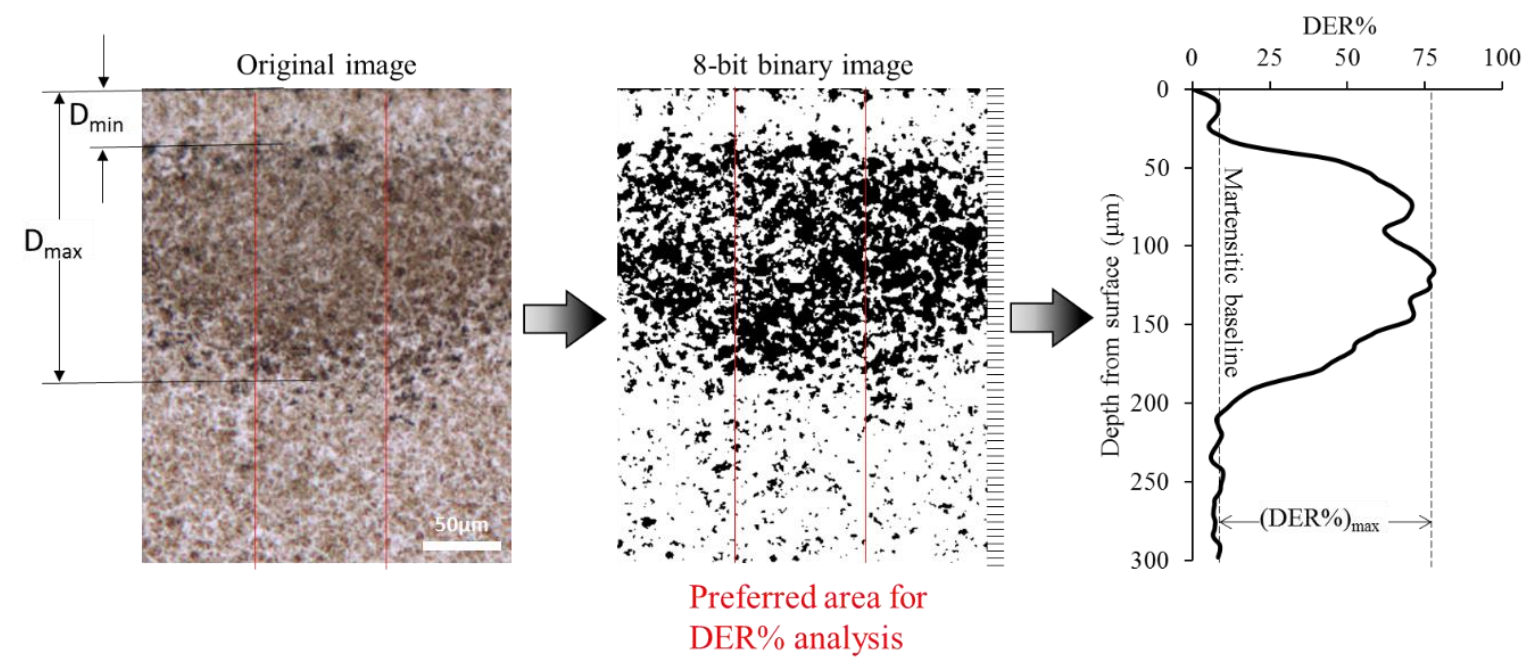

Figure 3. Evaluation of DERs on an axially sliced sample; original image converted to an 8-bit binary image and then analysed by layers of pixels with image processing code

\section{Results}

\subsection{Contact track evolution}

Contact track profiles were obtained from an optical interferometer Zygo NewView 5000 with a maximum resolution of $0.1 \pm 0.05 \mathrm{~nm}$. Data for contact track profile was acquired for a typical sample after successive stress cycles at given testing condition and plotted in Figure 4. Before measurement, samples were cleaned in an ultrasonic cleaner to remove any unwanted data noise. Figure 4(a) to 4(c) represents contact track profiles obtained during $6 \mathrm{GPa}$ contact stress with $40^{\circ} \mathrm{C}, 100^{\circ} \mathrm{C}$ and $160^{\circ} \mathrm{C}$ operating temperature whereas figure $4(\mathrm{~d})$ and $4(\mathrm{e})$ shows contact track profiles obtained at $160^{\circ} \mathrm{C}$ with $5 \mathrm{GPa}$ and $4 \mathrm{GPa}$ contact stress respectively. It can be noted that these contact track profiles represent 
build-up of plastic deformation with progressive stress cycles. For higher contact pressure and temperature, more pronounced plastic deformation was observed.

The high plastic deformation particularly at $160^{\circ} \mathrm{C}$ temperature, figure $4(\mathrm{c})$, indicates the cyclic softening and thermal tempering of the bearing ball material under RCF loading. Recall from section 1 that during the early stage of RCF loading, bearing ball material experiences significant plasticity after which no further plasticity is accumulated, known as initial plastic shakedown (Stage I). The small difference of the contact track plastic deformation obtained in figure 4 from a few million to tens of millions stress cycles even at 6GPa supports the argument that the bearing material operates under elastic deformation conditions during stage II. Early studies [17, 18] have reported similar behaviour for contact track evolution under rolling cycles. The slight difference in contact track profiles from 1 million to 37 million cycles is attributed towards accumulation of plasticity under cyclic loading. It can be noted that during the 4-ball test configuration, rolling cycles were carried out with minimal to no asperities interaction which leads to subsequent plasticity at contact track during rolling cycles.

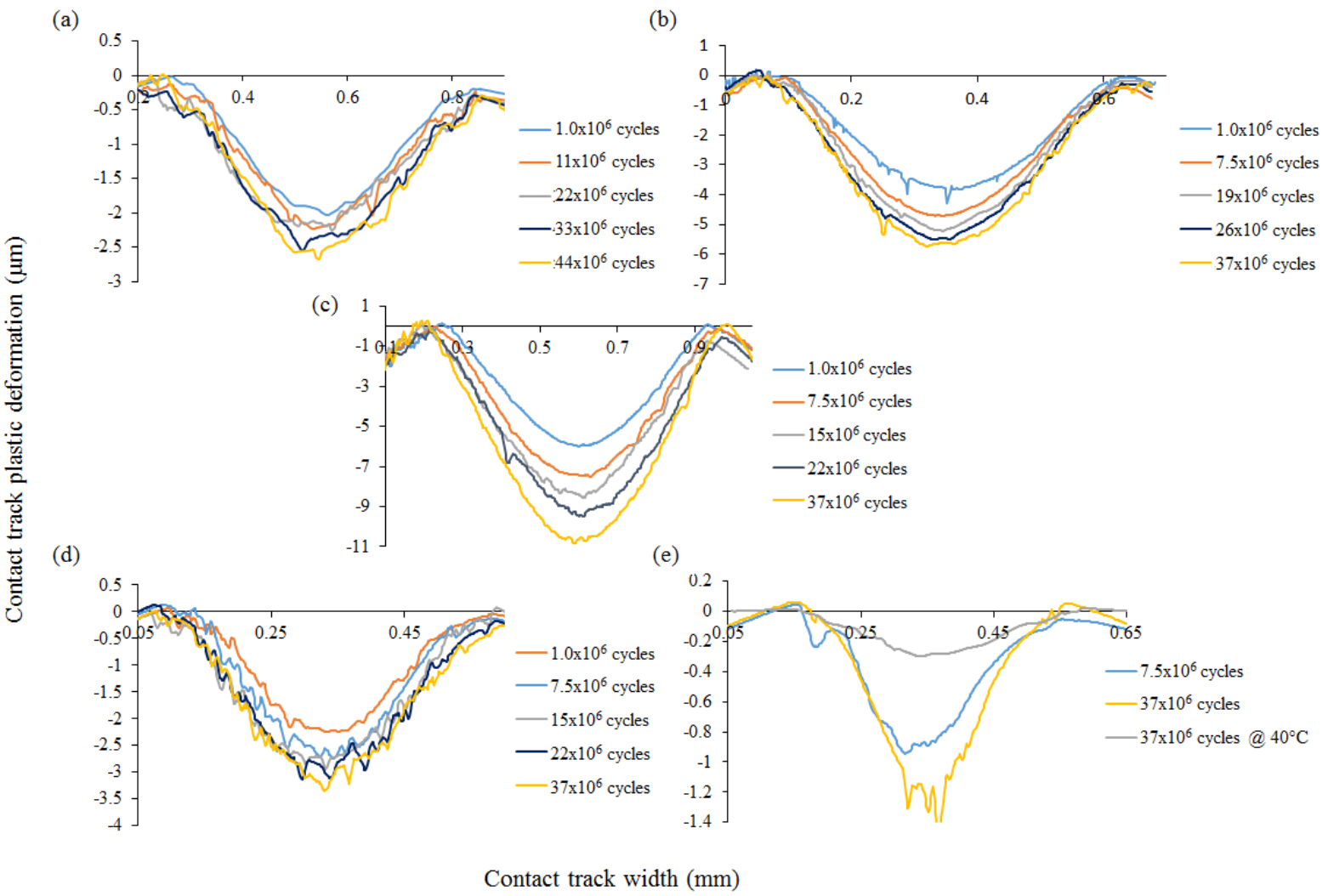

Figure 4. Contact track evaluation during RCF experimentations at $6 \mathrm{GPa}$ maximum Hertzian contact pressure with $40^{\circ} \mathrm{C}$, $100^{\circ} \mathrm{C}$ and $160^{\circ} \mathrm{C}$ operating temperature shown in (a), (b) and (c) respectively, whereas (d) and (e) represents $160^{\circ} \mathrm{C}$ with $5 \mathrm{GPa}$ and $4 \mathrm{GPa}$ contact pressure; legends represent respective stress cycles

\subsection{Dark Etching Regions (DER)}

The optical microscopy of the RCF tested bearing ball samples at $6 \mathrm{GPa}$ contact stress with $40^{\circ} \mathrm{C}$ operating temperature are shown in figure 5 where the axial slices and circumferential slices are shown after 5, 11 and 42 million stress cycles. It can be seen that after 5 million stress cycles, figure 5(a), no observable damaged or altered microstructure was observed under extremely high contact stress of 6GPa. However, after 11 million cycles, figure 5(b), the axial and circumferential slices of the sample exhibited a slight change in the subsurface zone which appeared persistent after 42 million stress cycles, figure 5(c). It can be noted that all the RCF tested bearing ball samples came from the similar 
composition of bearing steel as mentioned in Table 1. The subsurface alteration can be seen in the form of a dark ring for circumferentially sliced sample (top row, figure 5) whereas in axial slice (bottom row, figure 5) this dark region can be seen as a roughly semi-elliptical shape. Earlier RCF investigations [6, 8] were focused on the subsurface damage for inner raceway of the bearing where bearing elements make an elliptical contact with the inner raceway. Current research work utilises ball-on-ball point contact loading in a 4-ball tester which makes it distinguished from previously presented work on RCF induced subsurface microstructural alterations.

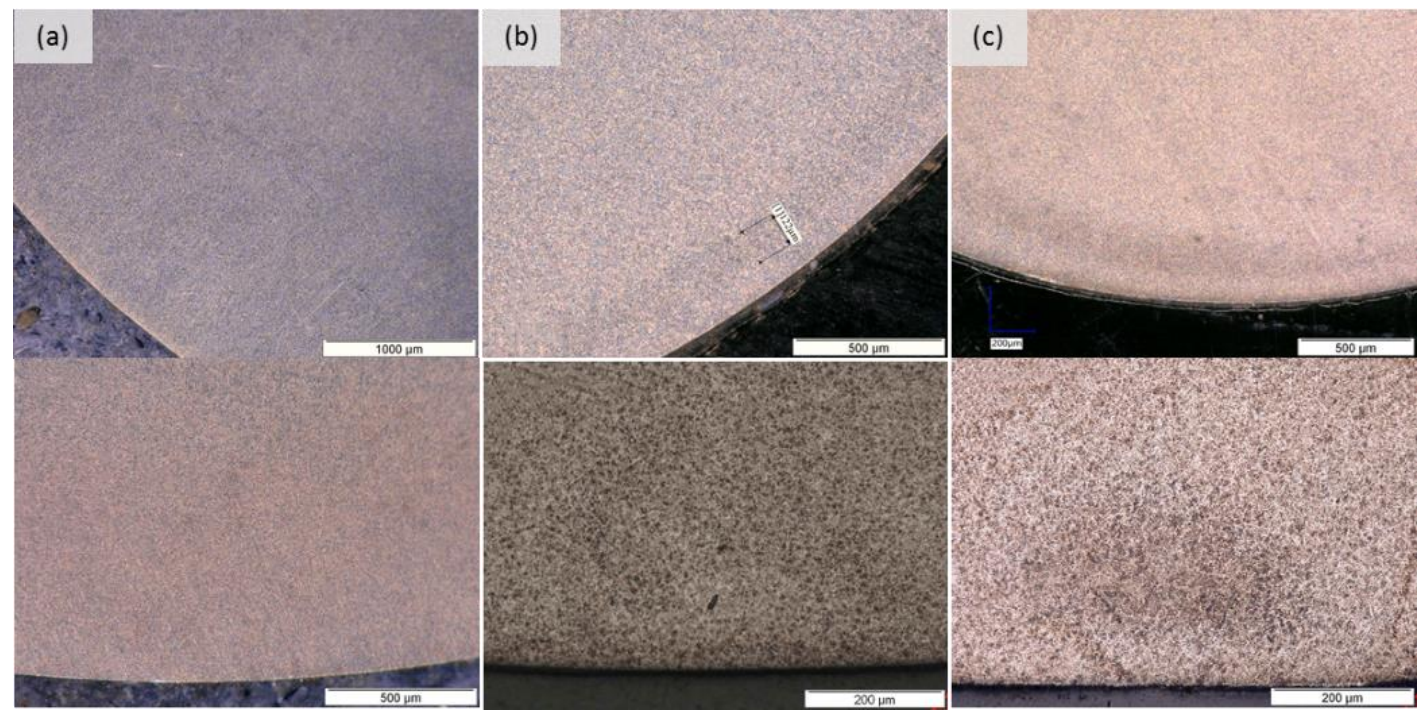

Figure 5. Optical microscopy images obtained from the circumferential (top row) and axial slice (bottom row) of RCF tested sample at $6 \mathrm{GPa}$ contact stress with $40^{\circ} \mathrm{C}$ operating temperature after (a) 5 million, (b) 11 million and (c) 42 million stress cycles.

Subsurface microscopic analysis for RCF tested bearing balls at an elevated temperature of $100^{\circ} \mathrm{C}$ with $6 \mathrm{GPa}$ contact stress are shown in figure 6 , where the micrographs are obtained from samples run at 1 , 5, 11, 22 and 37 million stress cycles. It can be noted that the initial 1 million stress cycles at $6 \mathrm{GPa}$, $100^{\circ} \mathrm{C}$ operating condition has resulted in the black patches formation under the contact track. This black patch formation can be observed to grow after 5, 11, 22 and 37 million cycles. It is important to know that the circumferential slice does not show the true depth of the DERs zone due to the slanted plane of cut (illustrated in figure 2). Owing to the unique mechanics of RCF loading condition in a 4ball test, it was not possible to slice the contact track parallel to the original rolling direction. However, the true visible RCF affected depth can be seen in the axial slice of each sample and have been used for measuring DER width, minimum/maximum depth and DER\% evaluation. After 22 million stress cycles, the micrographs in figure $6(\mathrm{~d})$ and 6(e) represents a white patch formation which is induced in the middle of contact track and can be seen in the axial and circumferential slices. This white patch formation is termed as WEBs which appeared with light contrast in bright field microscopy and are distinct from the black patches after Nital etching and shows strong resistance during etching process. A high resolution scanning electron microscope analysis for parent structure, DERs and WEBs were carried out for circumferential sliced samples and shown in figure 7. Figure 7(a) reveals a needle-like structure in the unrun virgin material where parent martensite along with primary $(\theta)$ carbides can be observed. Figure 7(b) represents a DERs zone where a distorted martensitic structure can be observed. Figure 7(c) shows WEBs constituents, marked with yellow lines, which can be observed more clearly in a magnified area in 7(d). The unique directionality of such WEBs is reported $[6,8]$ to be around $30^{\circ}$ and $80^{\circ}$ (as measured from the rolling direction) and is termed as lower angle bands (LABs) and higher angle bands (HABs). Figure 7(c,d) reveals that the white bands observed in the current study do not lie 
in either of these directions. The main reason for such directionality of bands can be explained by the circumferential plane of cut, illustrated in figure 2, which is slanted to the original plane parallel to the rolling direction. It can also be observed that the micrograph in figure 7(d) reveals premature white bands formation at 22 million cycles where minimal carbon depleted and carbon-rich areas can be observed.

The early formation of dark patches was also observed at $160^{\circ} \mathrm{C}, 6 \mathrm{GPa}$ under 1 million rolling cycles which starts to grow with progressive number of cycles, as shown in figure 8(a) to 8(e). However, at such elevated operating temperature, the formation of DER was accompanied by the development of more pronounced white bands. These white bands can be seen to form in the centre of DER region after 22 million cycles at $100^{\circ} \mathrm{C}$ temperature, figure $6(\mathrm{~d})$ and after 5 million stress cycles at $160^{\circ} \mathrm{C}$, figure 8(b). Due to the limited scope of this study, the formation of these white etching bands (WEBs) and their progression with respective stress cycles will be discussed in the future research work

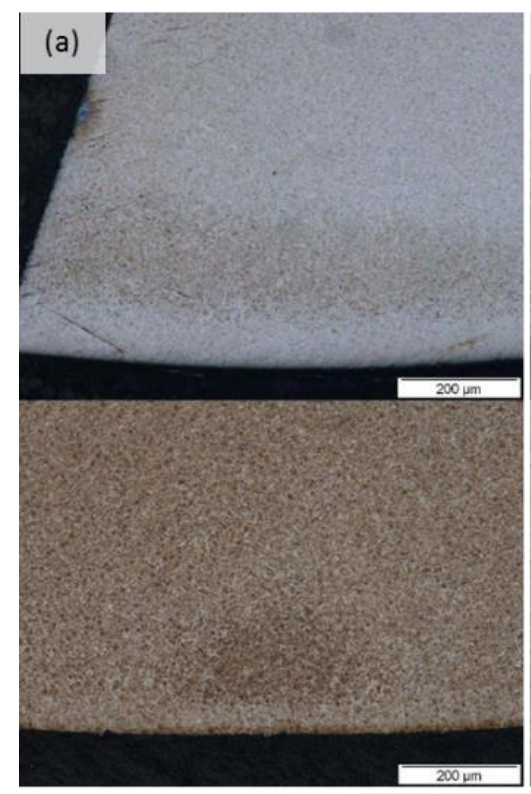

(d)

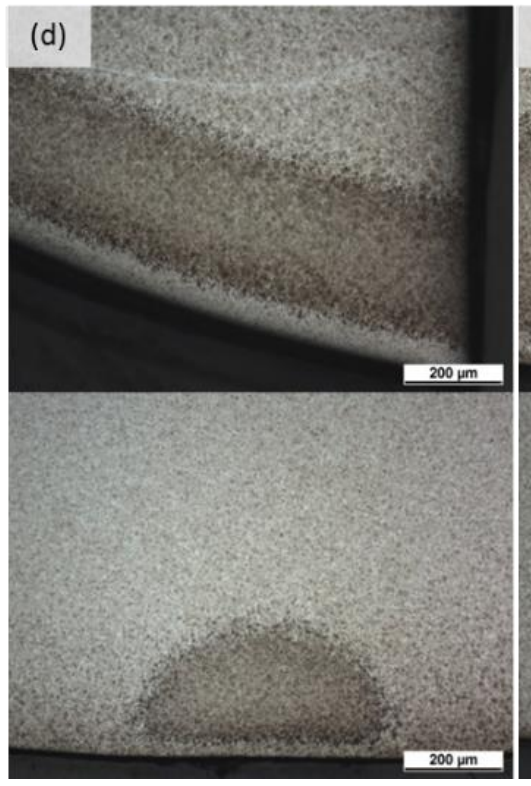

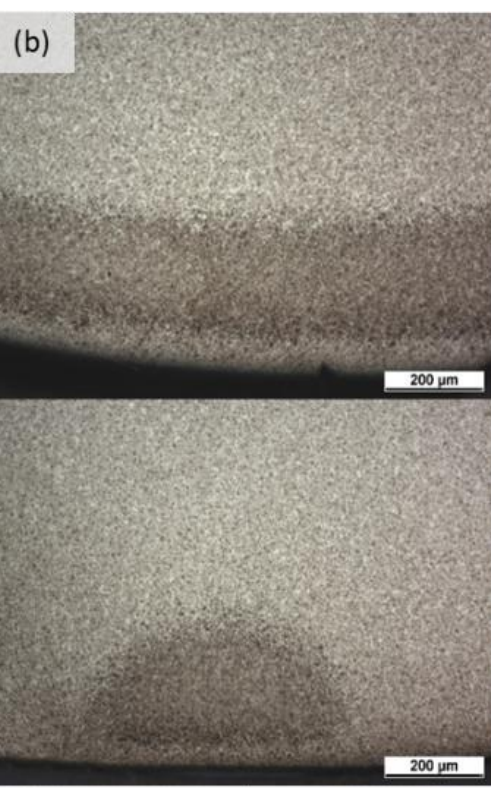

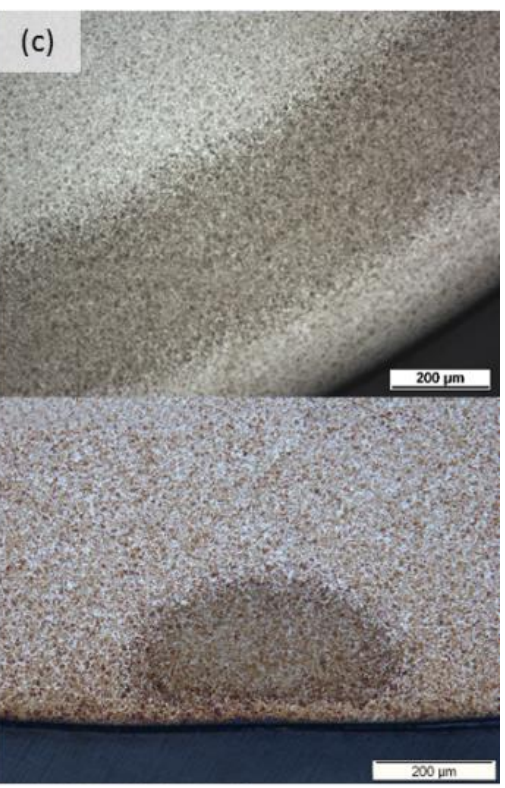

(e)

Figure 6. Optical microscopy of the RCF tested samples at $6 \mathrm{GPa}$ contact stress with $100^{\circ} \mathrm{C}$ operating temperature after $1 \times 10^{6}, 5 \times 10^{6}, 11 \times 10^{6}, 22 \times 10^{6}, 37 \times 10^{6}$ stress cycles from; (a) to (e) respectively. 


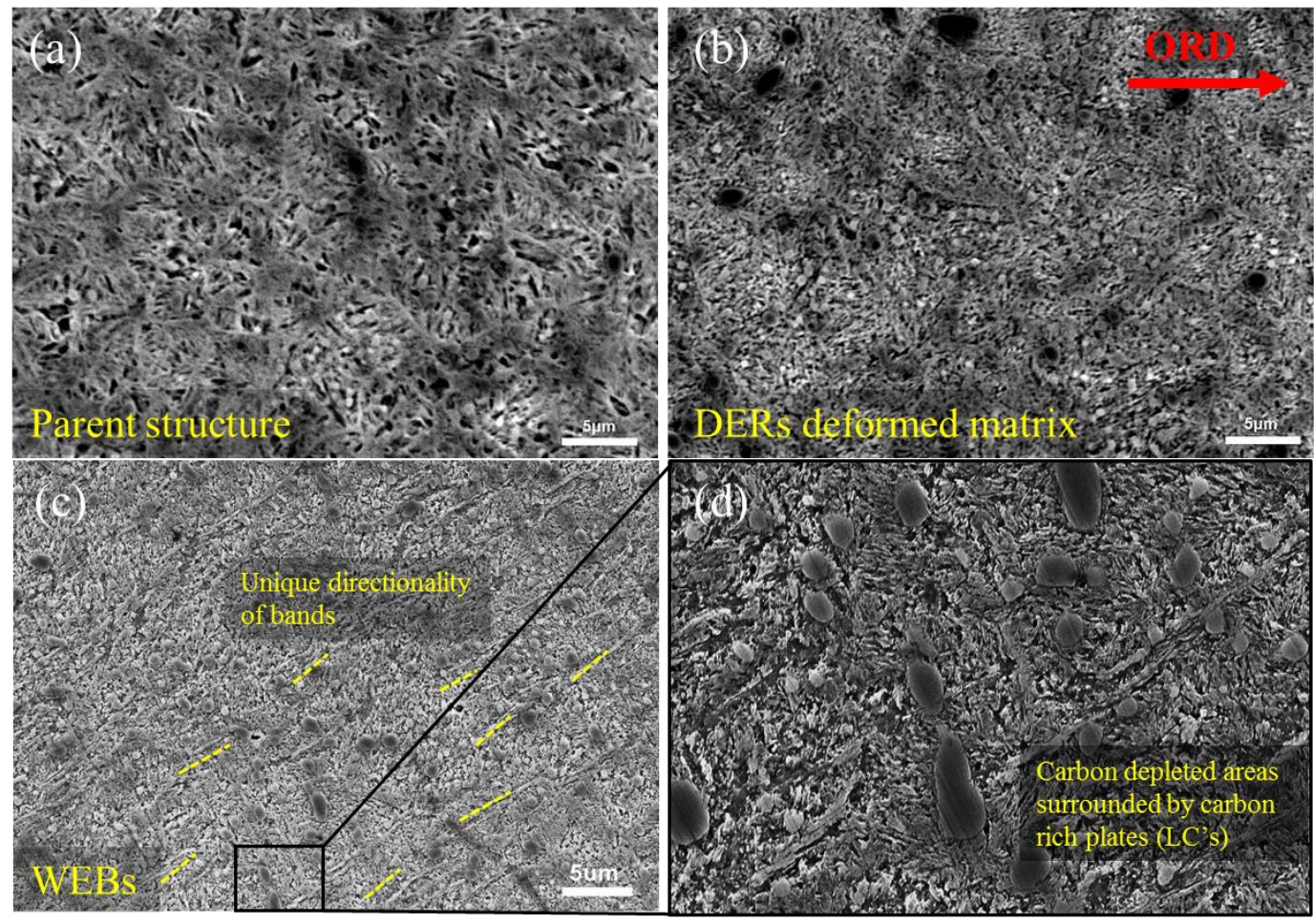

Figure 7. Micrographs of (a) parent martensitic structures (b) distorted structure formed during DERs formation (c) bands formation with unique directionality (d) zoomed-in area in (c); as observed from the circumferential cross-sections, original rolling direction denoted as ORD. 


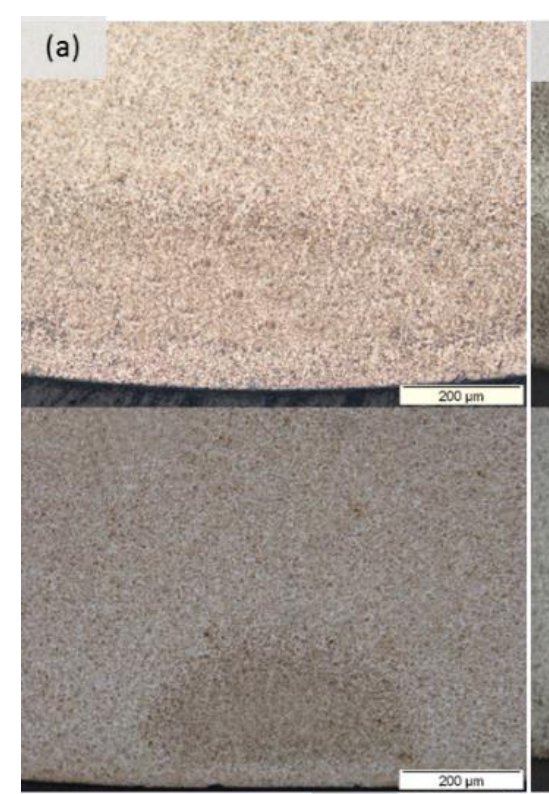

(d) (b)
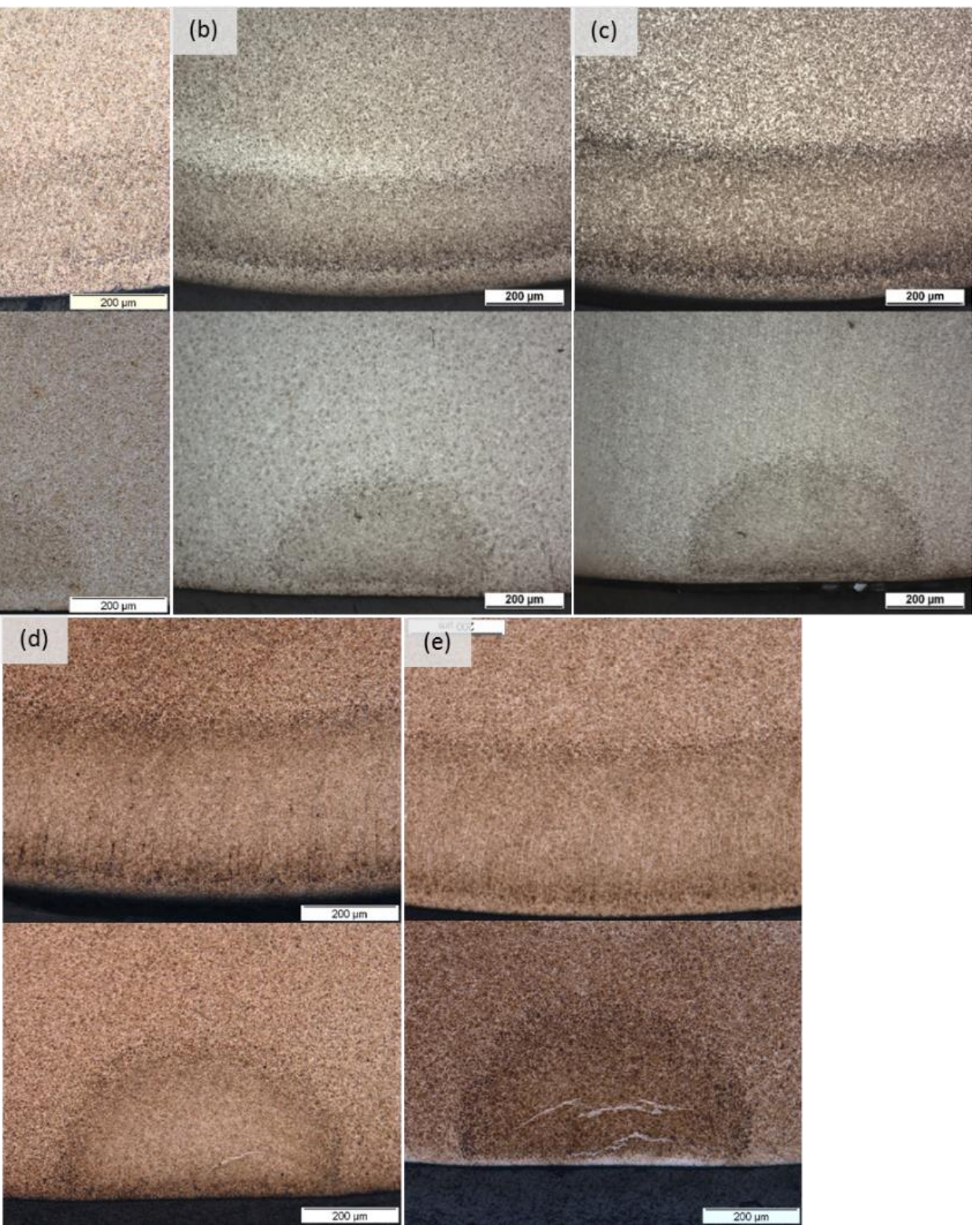

Figure 8. Optical microscopy of RCF tested samples at $6 \mathrm{GPa}$ contact stress with $160^{\circ} \mathrm{C}$ operating temperature after $\sim 1 \mathrm{x} 10^{6}$, $5.2 \times 10^{6}, 11 \times 10^{6}, 22 \times 10^{6}, 37 \times 10^{6}$ stress cycles as shown in figure (a) to (e) respectively.

As explained earlier, the effects of Nital etching can be observed more prominently with increased etching time, hence revealing subsurface alterations (black/white patches) with higher contrast under bright field microscopy. The RCF tested samples, obtained from $5 \mathrm{GPa}$ and $4 \mathrm{GPa}$ contact stress with $40^{\circ} \mathrm{C}$ temperature, are shown in figure 9(a) and 9(b) respectively. It can be seen that even after overetching of the ball bearing ball samples, no visible microstructure alteration was observed up to 37 million stress cycles. However, the samples tested at elevated temperatures of $100^{\circ} \mathrm{C}$ and $160^{\circ} \mathrm{C}$ showed considerable subsurface evolution. Figure 10 (a) to 10 (d) represent the $100^{\circ} \mathrm{C}$ temperature whereas 10 (e) to $10(\mathrm{~h})$ represent $160^{\circ} \mathrm{C}$ test at $5 \mathrm{GPa}$ contact stress where the samples were obtained after $5,11,22$ and 37 million cycles. Similarly, figure 11 (a) to 11 (c) represent the $100^{\circ} \mathrm{C}$ test and 11 (d) to 11 (f) show the $160^{\circ} \mathrm{C}$ test at $4 \mathrm{GPa}$ with 5,11 and 37 million rolling cycles respectively. The microscopic analysis presented in figure 5 to figure 11 reveal that the DER continue to grow in size (depth and width, as seen in axial slice) and can be defined by the extent of DER. Moreover, the area fraction of black patches under stressed zone also changes with progressive stress cycles depending upon level of stress and 
operating temperature. This area fraction of black patches was defined and calculated by DER\% for each testing condition and reported in section 5 .
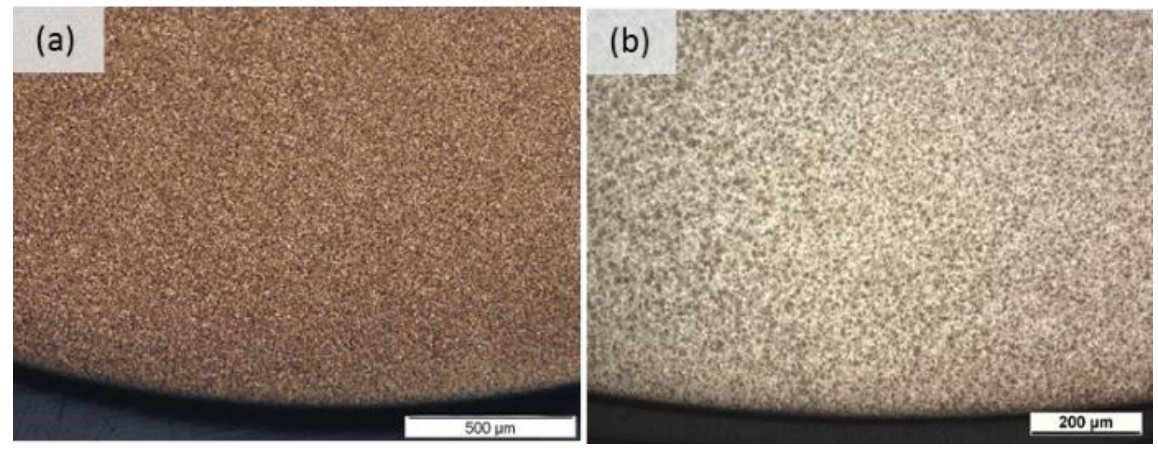

Figure 9. Over-etched samples obtained from axial cross-section of RCF samples tested at (a) $5 \mathrm{GPa}$ and (b) 4 GPa contact stress with $40^{\circ} \mathrm{C}$ operating temperature after 37 million cycles

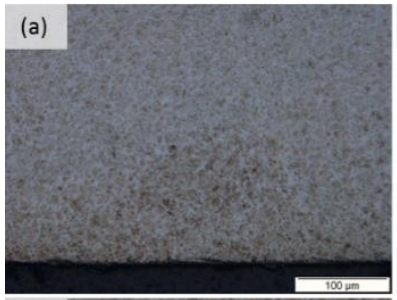

(e)

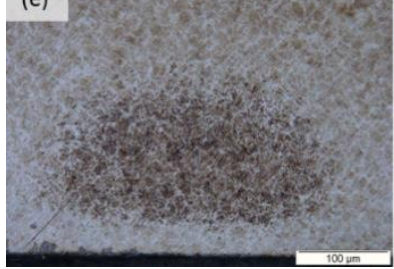

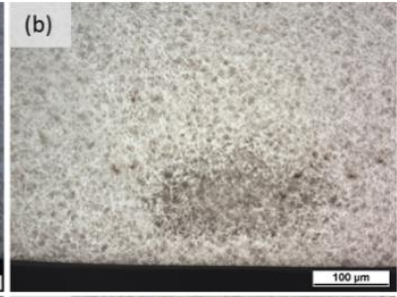

(f)

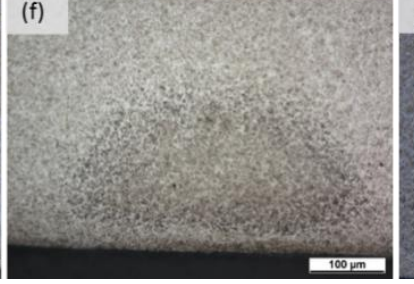

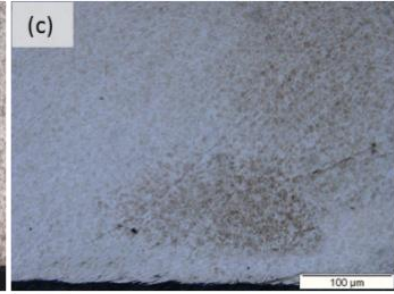

(g)

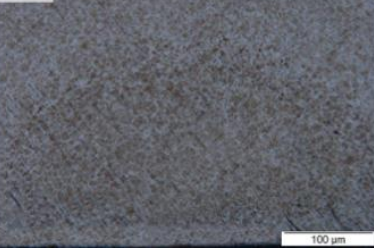

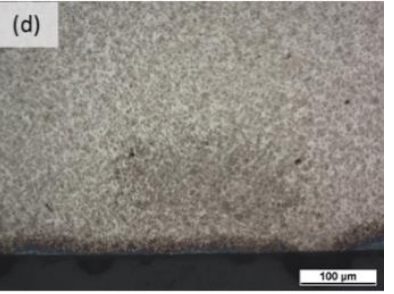

(h)

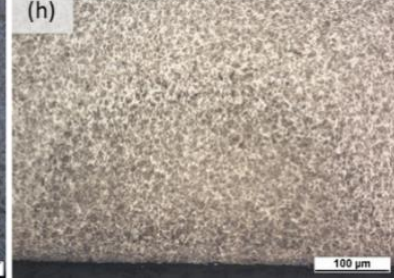

Figure 10. Micrographs obtained from axial sliced samples tested at $5 \mathrm{GPa}$ contact stress with $100^{\circ} \mathrm{C}$ operating temperature, (a) to (d), and $160^{\circ} \mathrm{C}$ operating temperature, (e) to (h), after $5 \times 10^{6}, 11 \times 10^{6}, 22 \times 10^{6}$ and $37 \times 10^{6}$ stress cycles

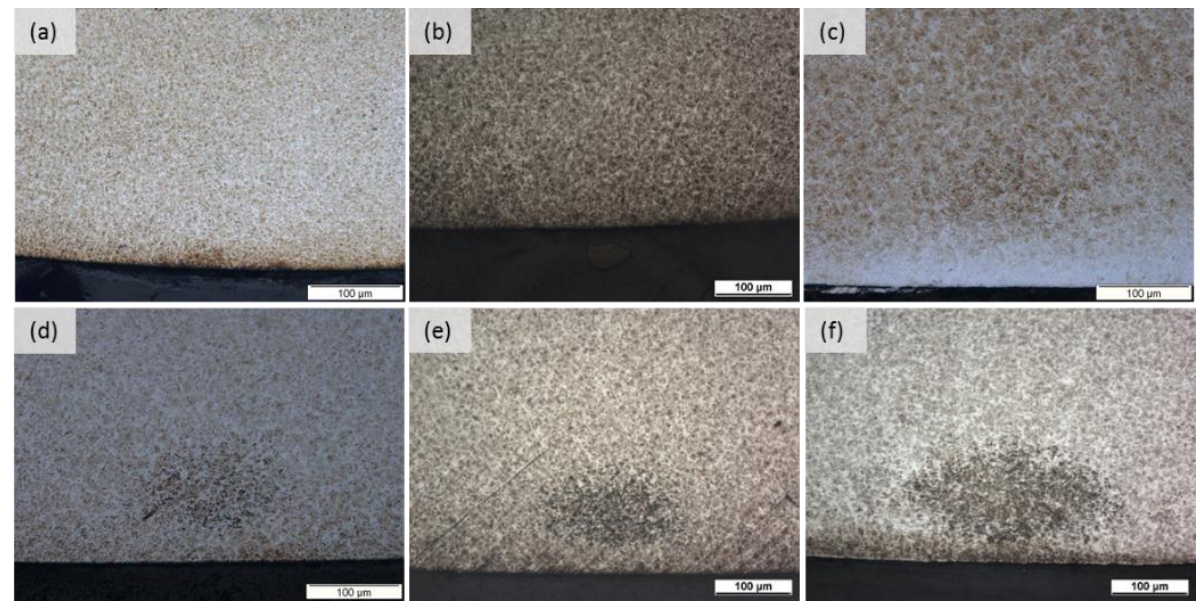

Figure 11. Micrographs obtained from axial sliced samples at $4 \mathrm{GPa}$ contact stress with $100^{\circ} \mathrm{C}$ operating temperature, (a) to (c), and $160^{\circ} \mathrm{C}$ operating temperature, (d) to (f), after $5 \times 10^{6}, 11 \times 10^{6}$ and $37 \times 10^{6}$ stress cycles

\section{Discussions}

Progression of RCF altered area with respective rolling cycles has been indicated in section 4.2. It can be observed that at higher contact stress and extreme operating temperature, the RCF altered area tend 
to grow in width (across sides of centreline contact track) and depth (towards the core of the material). To investigate the effect of thermal tempering on the growth of subsurface microstructure during rolling cycles, the observed extent of DER has been quantified in terms of width, minimum depth $\left(D_{\min }\right.$ and maximum depth $\left(\mathrm{D}_{\max }\right)$, as measured from the axial cross-section of bearing ball sample, and plotted for $6 \mathrm{GPa}$ contact stress with $160^{\circ} \mathrm{C}, 100^{\circ} \mathrm{C}$ and $40^{\circ} \mathrm{C}$ temperature, figure $12(\mathrm{a}-\mathrm{c})$. At fixed contact stress and temperature, the width and ' $D_{\max }$ ' of DER increased whereas the ' $\mathrm{D}_{\min }$ ' decreased with increasing rolling cycle.

Recall from section 4.1 that a contact track plastic deformation was significantly affected by the change in applied load, operating temperature and rolling cycles. The width of contact track is defined by $\mathrm{C}_{\mathrm{w}}$ and is obtained from interferometry analysis. It can be noticed that with progressive stress cycles, $\mathrm{C}_{\mathrm{w}}$ gradually increases. The continuous widening in contact track is similar to growth in DER width, however, no direct comparison can be observed between DER width and $\mathrm{C}_{\mathrm{w}}$. The maximum plastic depth from interferometry is characterised as $\mathrm{D}_{\mathrm{p}}$ and is measured from the shoulders of the contact track profile (refer to figure 4). The observed $D_{p}$ values are plotted in figure 12 with corresponding stress cycles and compared with the width of DER. It is evident that the ' $\mathrm{D}_{\mathrm{p}}$ ' increased in a similar manner as DER width with increasing cycles at certain load and temperature. The contact track evolution under Hertzian contact represents the accumulation of plasticity with each rolling cycle. The build-up of plasticity during rolling cycles indicates the ratcheting response of bearing ball material, where the micro-strains are accumulated with each consecutive rolling pass at subsurface under Hertzian contact. The continuous accumulation of plasticity can be seen at $40^{\circ} \mathrm{C}$, where the DER region also tends to grow with progressive cycles. However, at $100^{\circ} \mathrm{C}$, the plasticity accumulation tends to cease after 22 million cycle as indicated in figure 12(b) where the DER growth also ceased. This leads to a fully grown DER zone obtained at 22 million cycles after which no further growth in DER size was observed. It can be noted that at $160^{\circ} \mathrm{C}$ operating temperature, the DER region was growing unceasingly along with the accumulation of plasticity which reveals the role of thermal tempering and lowering of yield stress at a temperature as high as $160^{\circ} \mathrm{C}$ which is quite close to the tempering temperature of bearing steel. The relationship between $D_{p}$ and DER width demonstrates the growth of DER with accumulation of plasticity e.g. a continuous plasticity accumulation will result in the progression of DER extent. The fully grown DER observed at $100^{\circ} \mathrm{C}$ after 22 million cycles can also be explained by the seizure of RCF induced plasticity at given conditions. 
(a)

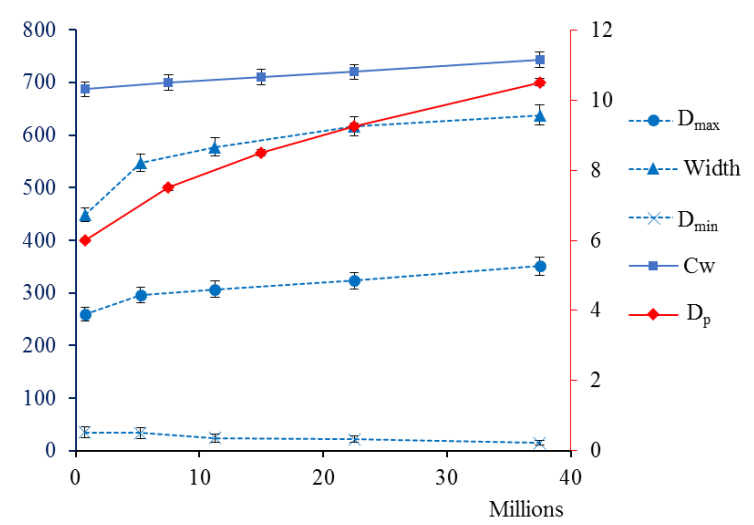

(b)

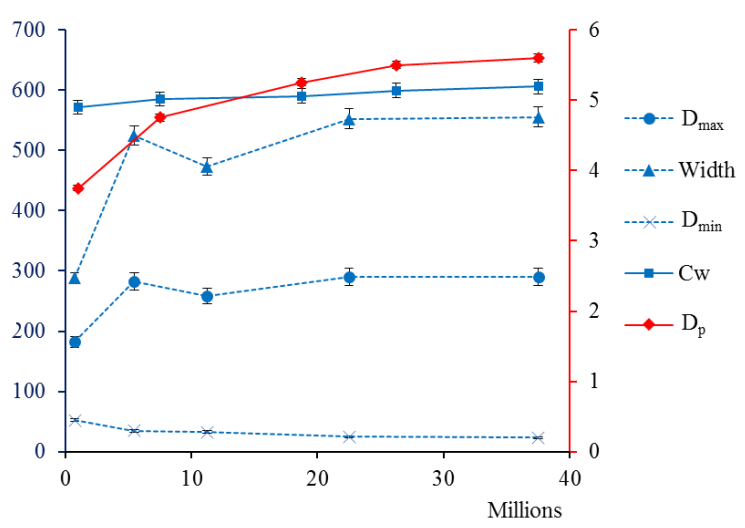

(c)

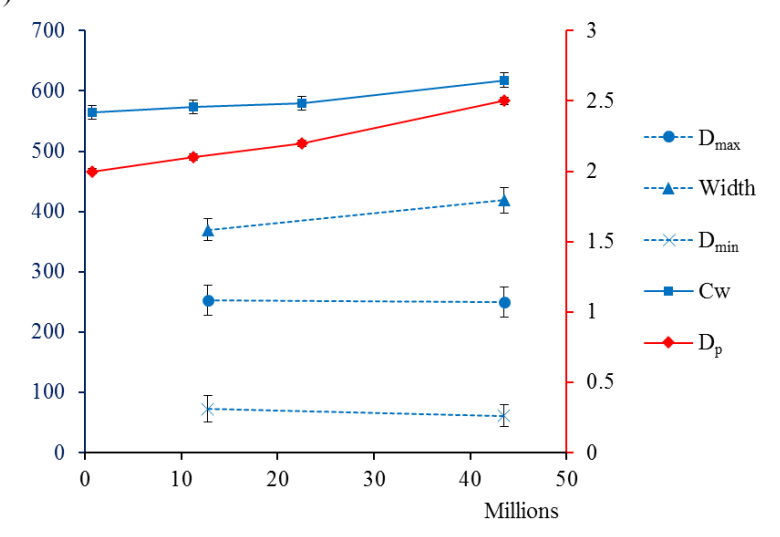

Figure 12. DER initial, maximum depth and width ( $D_{\min }, D_{\max }$, Width) along with contact track plastic width and depth $(\mathrm{Cw}$ and $\mathrm{Dp}$ ) plotted for various stress cycles at $6 \mathrm{GPa}$ contact pressure with (a) $160^{\circ} \mathrm{C}$ (b) $100^{\circ} \mathrm{C}$ (c) $40^{\circ} \mathrm{C}$ operating temperatures; characteristic lengths at primary and secondary vertical axis are given in $\mu \mathrm{m}$.

Subsurface optical microscopy images from each RCF test analysed with image processing generated the DER\% profiles after martensitic baseline correction. Figure 13(a) represents the threshold image for DER black patches formed after 1,11 and 37 million stress cycles at $100^{\circ} \mathrm{C}$ operating temperature, while figure 13(b) shows the DER\% quantified through the depth below contact track. It can be noted that the maxima for acquired DER\% tend to increase significantly from 1 to 11 million cycles where a fully developed DER region can be seen in form of $\sim 100 \%$ DERs. Further increase in the rolling cycle at $6 \mathrm{GPa}, 100^{\circ} \mathrm{C}$ test condition can be observed to cause a drop in the maxima for DER. The sudden drop of DER\% indicates the white patches development which starts at $125 \mu \mathrm{m}$ depth and spread on either side of this maxima, refer to figure 13(b). The overall maxima of DER\% was reduced from 95\% to $65 \%$ after 37 million cycles and the far-side DER depth was found wider representing growth of DER extent as explained earlier. This white patch development is manifested as WEBs and they are further classified in lower angle bands (LABs) and higher angle bands (HABs). A more recet study [19] has identified the WEBs position in the middle of DERs zone. It was reported that WEBs formation tends to grow at a position such that the DER becomes no longer visible. As the white bands grow with increasing stress cycles, the DER maxima tend to decrease accordingly.

The boundaries of a DER region as seen in figure 13(b) can be observed sharp towards the initiating side and slightly diffused towards the core of the material which can be explained with responsible stress component to cause DER. Previous studies $[3,4,7,20]$ have attributed the cause and formation of DER due to strain-induced martensite decay where the reported stress components are von Mises stress $\left(\mathrm{S}_{\text {Mises }}\right)$, Maximum shear $\left(\tau_{45, \max }\right.$, acting $45^{\circ}$ to the rolling direction $)$ and orthogonal shear stress ( $\tau_{0}$, acting normal and parallel to the contact surface). These stress components, obtained from Hertzian 
elastic theory for ball-on-ball point contact, at 6GPa contact pressure have been plotted in figure 13(b) and compared with the obtained DER profiles. It can be seen that the limiting boundaries of the DER initiation and termination have strong relation to the plotted stress profiles. Moreover, the careful comparison of measured percentage DERs for 37M cycles reveals that the formation of white bands can be seen at a depth range where the $\tau_{45 \text {, max }}$ acts below the centreline contact track. The unique directionality of WEBs is around $25^{\circ}-30^{\circ}$ for lower angle bands and $70^{\circ}-80^{\circ}$ for higher angle bands [3, 8]. It has been reported [21] that these formation mechanism of WEBs is governed by the position and direction of maximum shear stress. A more recent study [22] has also demonstrated that the ferrite bands within WEBs manifest shear plastic strains which accumulates during RCF. Current research work outlines similar findings after detailed comparison of stress profiles at $6 \mathrm{GPa}$ with corresponding DER\% investigation as shown in figure 13.

(a)
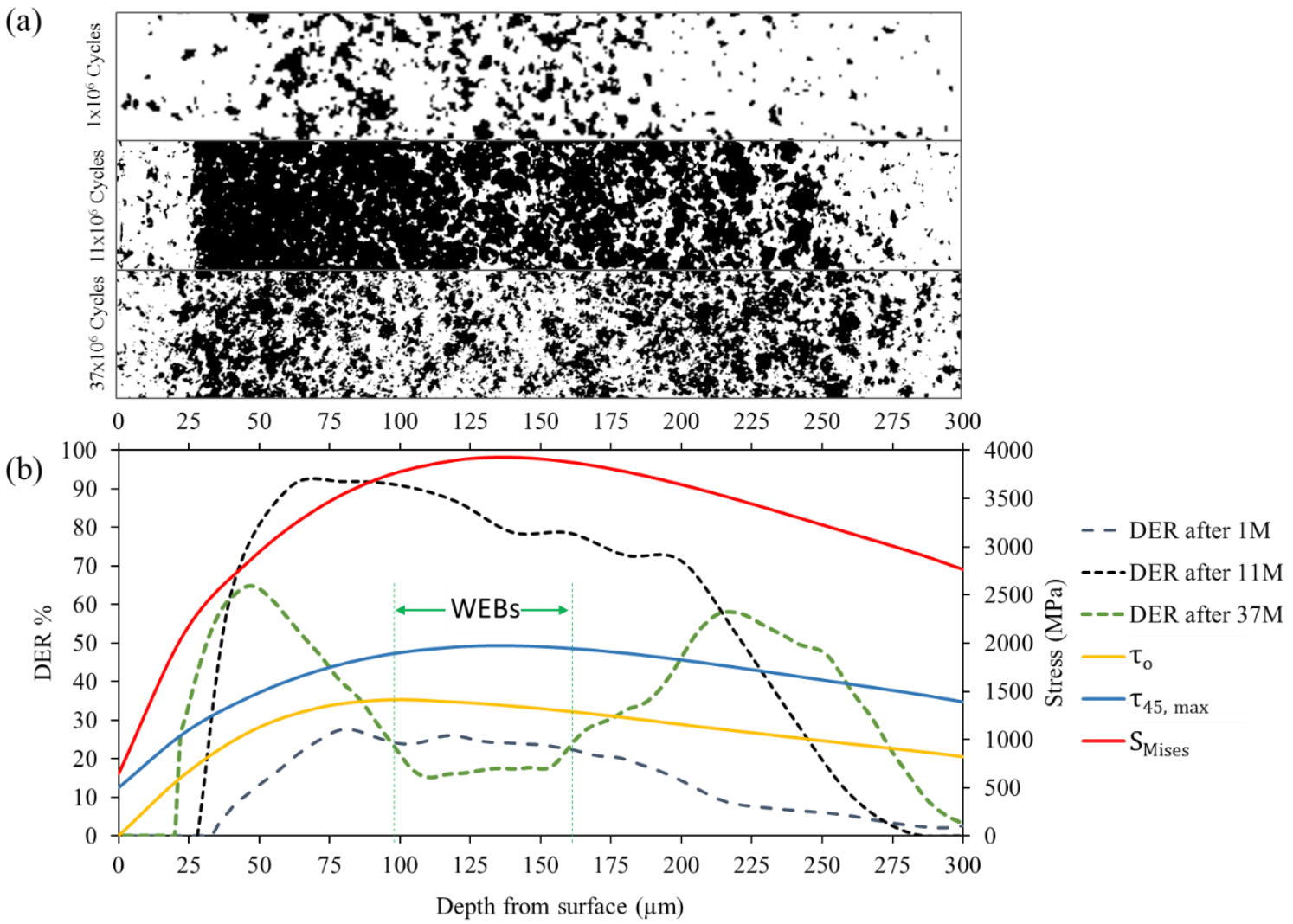

Figure 13. Structural development during RCF loading cycles at $6 \mathrm{GPa}, 100^{\circ} \mathrm{C}$ (a) represents threshold images for DER evaluation (b) acquired DER\% profiles at $1,11 \& 37$ million cycle along with stress components

It has been observed that the formation of subsurface alterations (DERs + WEBs) were quite significant at $6 \mathrm{GPa}$ contact pressure so it was quite difficult to isolate the distinctive stress component to cause DER formation. Figure 14(a, b) represents the DER\% profiles obtained at 4GPa with 37 Million and 5GPa with 5 Million stress cycles, assuming to be a starting point for DER initiation under given conditions. These investigated DER profiles are compared with $\tau_{0}, S_{\text {Mises }}$, and $\tau_{45 \text {,max }}$ stresses at respective load levels.

Figure 14(a) reveals that the maxima of the percentage DERs at 4GPa marginally matches with the depth range where the maxima of $S_{\text {Mises }}$ and $\tau_{45 \text {, max }}$ exist below contact track. A similar trend has also been considered for figure $14(\mathrm{~b})$ at $5 \mathrm{GPa}$ with $100^{\circ} \mathrm{C}$ and $160^{\circ} \mathrm{C}$ temperature. Earlier research work has reported the DER depth range to be assciated with $\tau_{0}$. The discrepancies of the responsible stress components for DER formation can be better understood by maximum distortion energy yield criteria 
in multiaxial state of stress. As suggested by Zwirlein and Schlicht [20], the RCF induced microstructural alterations are mainly governed by equivalent or von Mises stresses, obtained from maximum distortion energy theory. In a recent study [19], it has been described that the DERs cannot be explained by considering maximum shear stresses.

The equivalent stress also referred to as von Mises stress acts below the Hertzian contact geometry and its maxima is observed at a depth $\mathrm{z}=0.48 \mathrm{a}$ across centreline contact track, where $\mathrm{b}$ denotes semi-minor axis. As discussed earlier, the continuous cyclic stressing causes accumulation of plasticity which generates subsurface compressive residual stresses (RS). In addition to the plasticity induced residual stress, a certain amount of residual stresses are also associated with the volume fraction of microstructural phase transformations i.e. decay of retained austenite and parent martensite. A.P. Voskamp [6, 13] during the endurance testing of deep groove ball bearings (DGBB) has reported continuous growth of these deep zones compressive residual stresses. Taking into account this most important subsurface changes caused by RCF, residual stresses, the formation mechanism of DER can be explained. Figure 15 shows the von Mises stress obtained at centreline contact track from elastic theory, along with the extensive residual stress experimental data reported in literature [6]. The centreline depth from contact has been normalised with semi-minor half-width due to the difference in contact geometries of DGBB and 4-ball configuration $(b=0.502 \mathrm{~mm}$ for inner raceway of DGBB elliptical contact and $0.1763 \mathrm{~mm}$ for ball-on-ball point contact). The absolutely no WEB superposition of residual stress on the equivalent von Mises stress is represented as $S_{\text {evol }}$ which can be seen to evolve after 1, 10 and 100 million rolling cycles. The maxima for DER\% profile from 5 million to 11 million cycles lie in range of $0.33 \mathrm{~b}$ to $0.48 \mathrm{~b}$ as shown in figure 15 . This maxima closely matches with the $\mathrm{S}_{\text {evol }}$ after 10 million cycles. The continuous evolution of residual stress during cyclic loading cause a shift in the peaks of $S_{\text {evol }}$ which can be observed to shift more towards the contact track after 10 and 100 million cycles. Moreover, the superposition of residual stress on the von Mises profiles also flattens the peak of the stress profile where its maxima lie in a wider depth similar to the DER\% @11Million. It is pertinent to know that the residual stress data was investigated from testing of a standard AISI-52100 bearing steel at a maximum contact pressure of $3720 \mathrm{MPa}$ with an operating temperature of $50^{\circ} \mathrm{C}$. Hence any comparison here would give more qualitative analysis of how the equivalent stresses evolve and its subsequent effects on microstructural alterations. In addition, the contact track plasticity as reported in section 4.1 also influence the subsurface equivalent stresses due to change in semi-minor and semimajor half widths where an increased half-width of $0.201 \mathrm{~mm}$ was observed at $4 \mathrm{GPa}$ with $40^{\circ} \mathrm{C}$, see figure 4(c), as compared with $0.1763 \mathrm{~mm}$ obtained from elastic theory. The strong relation of evolved Mises stress profiles with corresponding DER evaluation curves supports the argument that these microstructural changes are influenced by the equivalent stress where the von Mises stress governs plasticity with the superposition of subsurface residual stress. It is possible to say that the early subsurface microstructural alterations i.e. DERs can be governed by the evolved von Mises stresses, whereas the later progression and development of WEBs (due to depth distribution and unique directionality) can be controlled by the maximum principal shear stresses. 
(a)

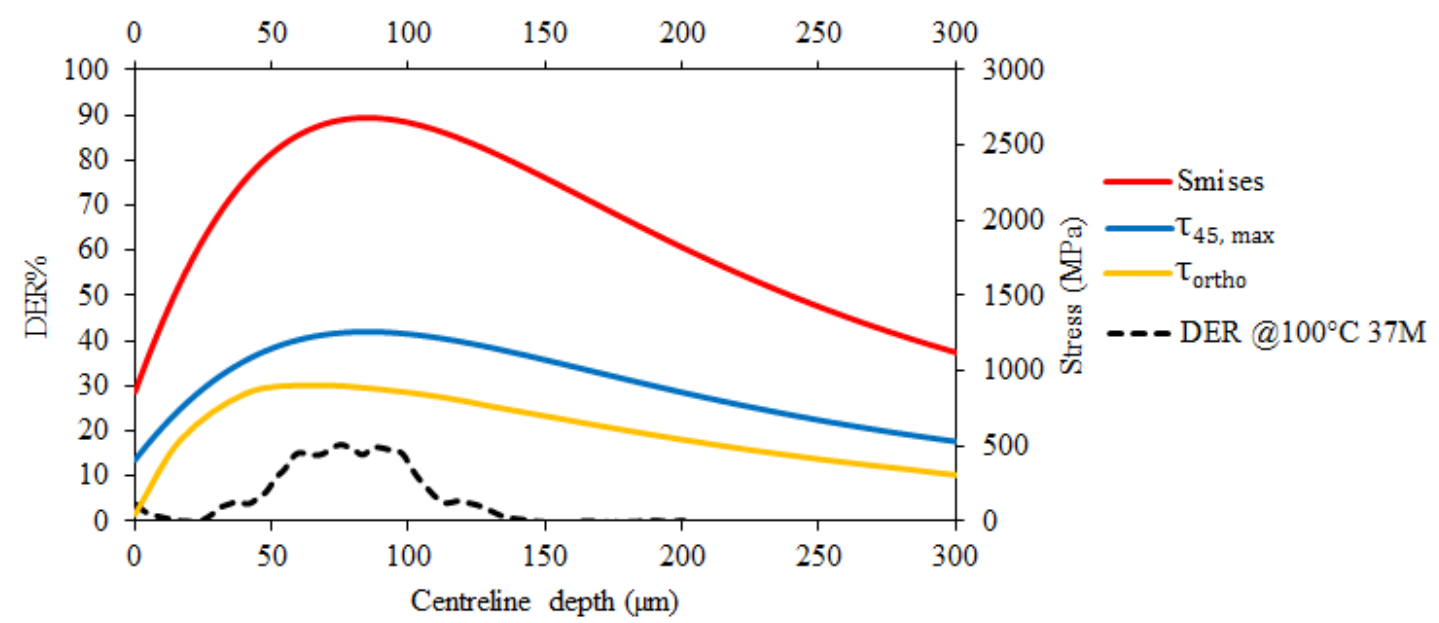

(b)

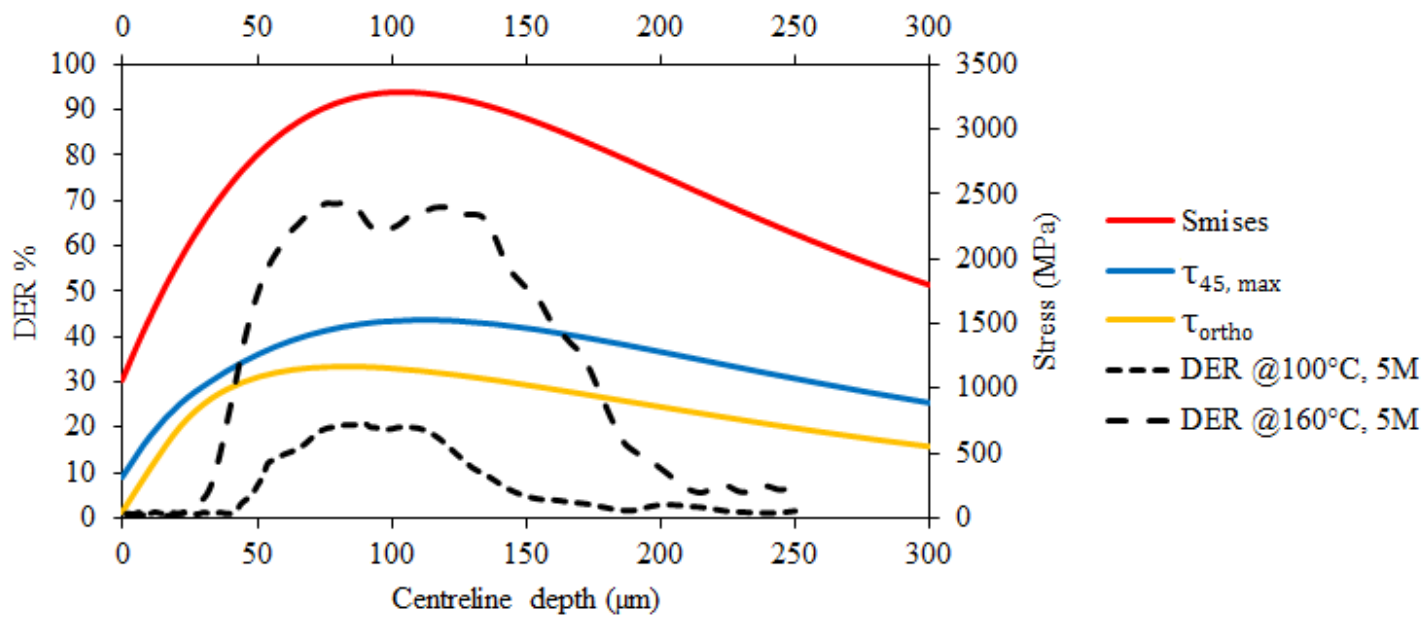

Figure 14. DER\% profiles at (a) 4GPa and (b) 5GPa contact pressure after 5million cycle, the corresponding stress components are plotted for comparison 


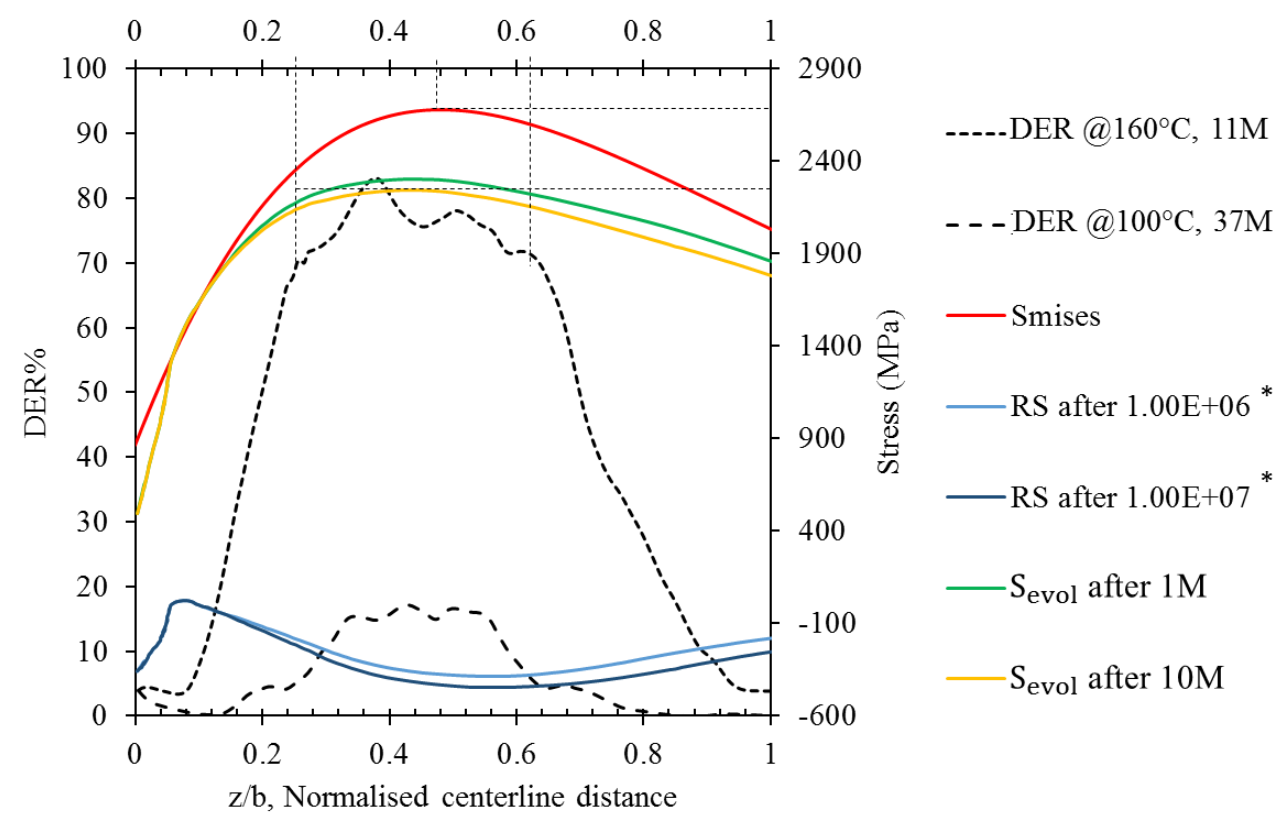

Figure 15. Von Mises stress with and without the inclusion of subsurface residual stress; * data obtained from the testing of DGBB [6]

As discussed earlier the formation of DER is influenced by accumulation of cyclic plasticity where the formation and progression of DER highly depend on contact stress and operating temperature. To understand the effect of applied load and temperature during RCF test on DER development, it is vital to investigate the local DER\% at a critical depth where the von Mises stress maxima acts. Figure 16 represents the evaluated DER\% for each RCF tested sample at 4, 5 and 6GPa contact pressure, where DER\% have been plotted against progressive stress cycles with temperature variation. Figure 16(a) and figure $16(\mathrm{~b})$ shows a similar trend at $40^{\circ} \mathrm{C}$ and $100^{\circ} \mathrm{C}$ with a gradual increase in DER formation and then a plateau. At $6 \mathrm{GPa}$ contact stress with $40^{\circ} \mathrm{C}$ operating temperature, DER start to build up after 11 million with a very minimal area of subsurface alterations which gradually increases till 37 million cycles. For $100^{\circ} \mathrm{C}$ operating temperature, DER formation initiates within 1 million stress cycles and then saturates after 11 million cycles where a fully developed DER region can be observed. After 11 million stress cycles a slight decrease in the DER\% maxima can be seen with increasing stress cycles. This continuous decrease persists to 37 million cycles and supports the argument of WEBs growth. Hence, at $6 \mathrm{GPa}, 100^{\circ} \mathrm{C}$ condition, 11 million rolling cycles would become the initiating point for WEBs.

At $160^{\circ} \mathrm{C}$ operating temperature, the fully saturation of DERs followed by the development of WEBs can be observed at 5 million rolling cycles, where the black patches to white patches transition take place and overall DERs gradually increase till 11 million cycles. A decreasing DER\% can be noticed afterwards which states the favourable formation of WEBs at elevated temperature of $160^{\circ} \mathrm{C}$. The formation of WEBs in a very early stage of RCF (i.e. 5 million cycles) can be explained by the high plastic deformation at $6 \mathrm{GPa}, 160^{\circ} \mathrm{C}$ operating temperature which causes thermal tempering of steel and significantly alters the coherency of nanosized carbides in the steel matrix [13, 23], which lead to a reduced dark etching response. Moreover, $160^{\circ} \mathrm{C}$ temperature is quite close to the tempering temperature of bearing steel, which leads to an undissolved carbon in the matrix solution and is highly favourable for WEBs formation. 
(a)

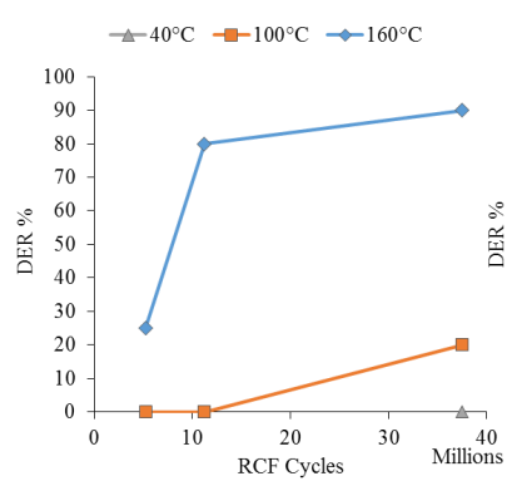

(b)

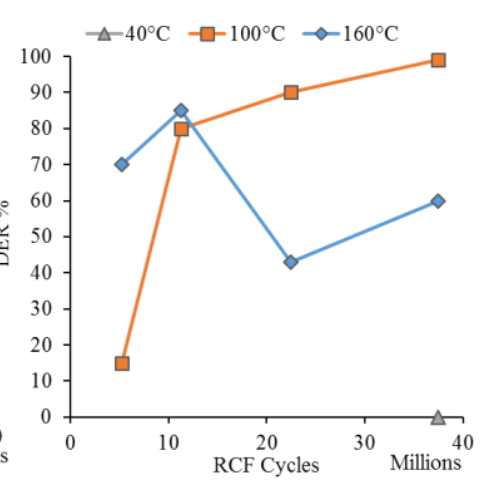

(c)

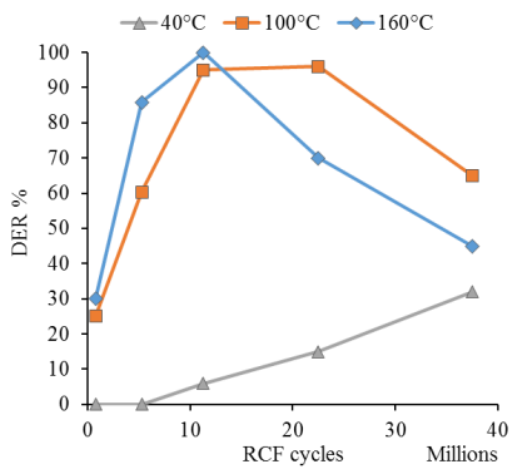

Figure 16. Local DER\% measured at critical depth below contact track at 4,5 and 6 GPa shown in (a), (b) and (c) respectively

To understand the combined effect of contact stress and temperature variation on overall DER growth, global maximum DER\% (represents the maximum observable DER\% under contact track) was also plotted for all temperature and contact stress variation and represented as a 3D-DER\% Map, see figure 17(a), whereas the respective DER\% contours are shown in figure 17(b) for 1,5,11 and 22 million rolling cycles. The DER\% calculated at 37 million cycles was found similar in range as 22 million cycle, hence not displayed in figure 17. Within 1 million rolling cycles, no DERs formation was observed for $40^{\circ} \mathrm{C}$ even at extremely high contact stress of 6GPa. The purpose of acquiring global maximum DER\% instead of local DER\% at representative depth is to exclude the effects of WEBs in DERs assessment.

It can be noted that the DERs can be seen to increase from $25 \%$ to $\sim 100 \%$ while the temperature is increased $40^{\circ} \mathrm{C}$ to $100^{\circ} \mathrm{C}$ and $160^{\circ} \mathrm{C}$ after 11 million and 5 million cycles respectively. It is evident from figure 17 that WEBs were not observed within initial 11 million RCF cycle for 5 and 6GPa contact pressure, whereas at $4 \mathrm{GPa}$, absolutely no WEB formation was observed. The reported extensive DER formation data can be used as a guideline to model the DERs formation and to predict the initiation and progression of structural alterations with corresponding stress cycles under given conditions. The formation mechanism of such microstructural alterations in particular DERs have been modelled earlier with dislocation assisted carbon migration flux $[4,9]$ where the decay of parent martensitic structure has been associated with the dislocation gliding during cyclic plasticity. The experimentally measured global maximum DER\% presented in current research have been compared with previously reported DER formation numerical models. 
(a)

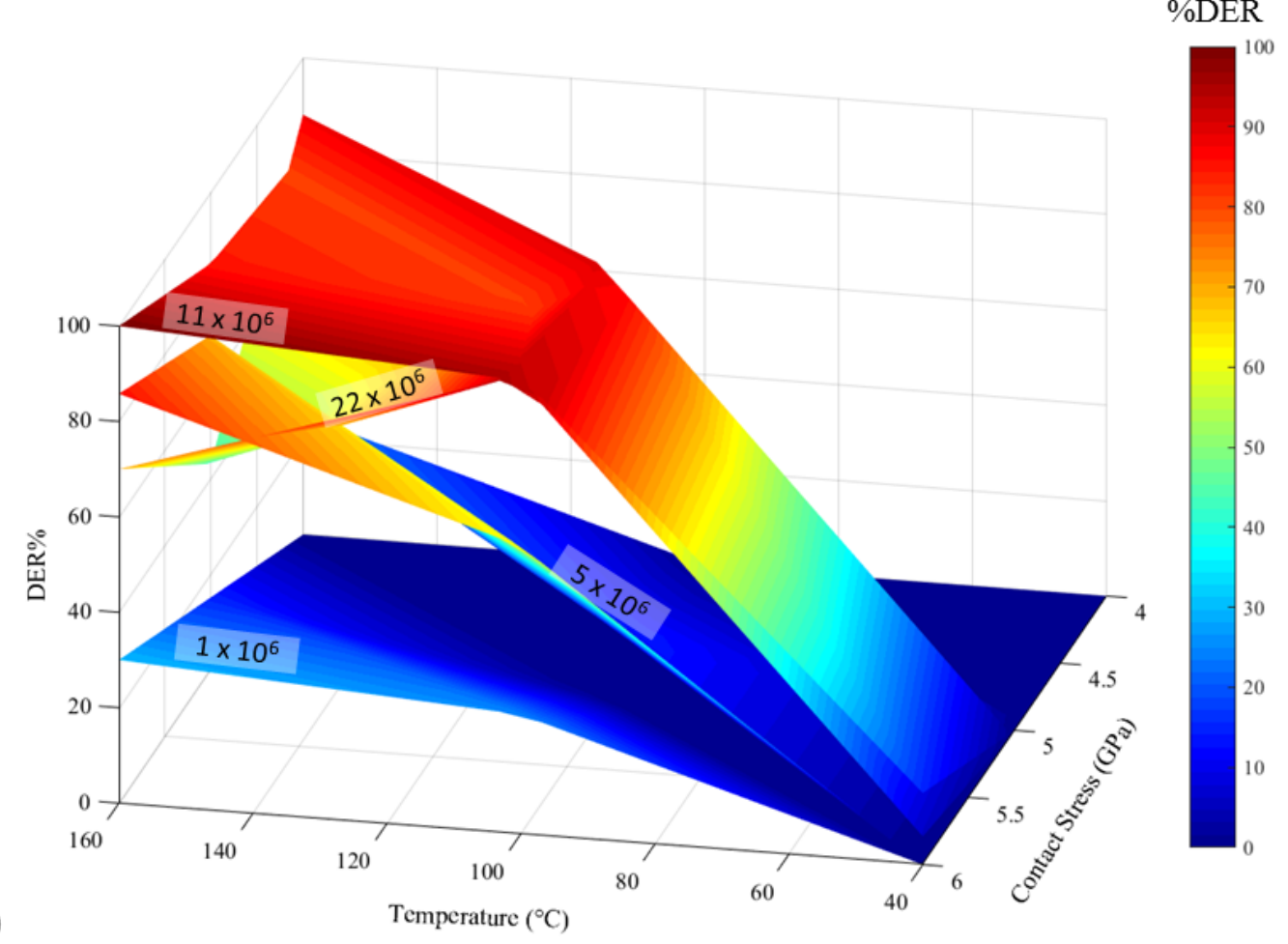

(b)
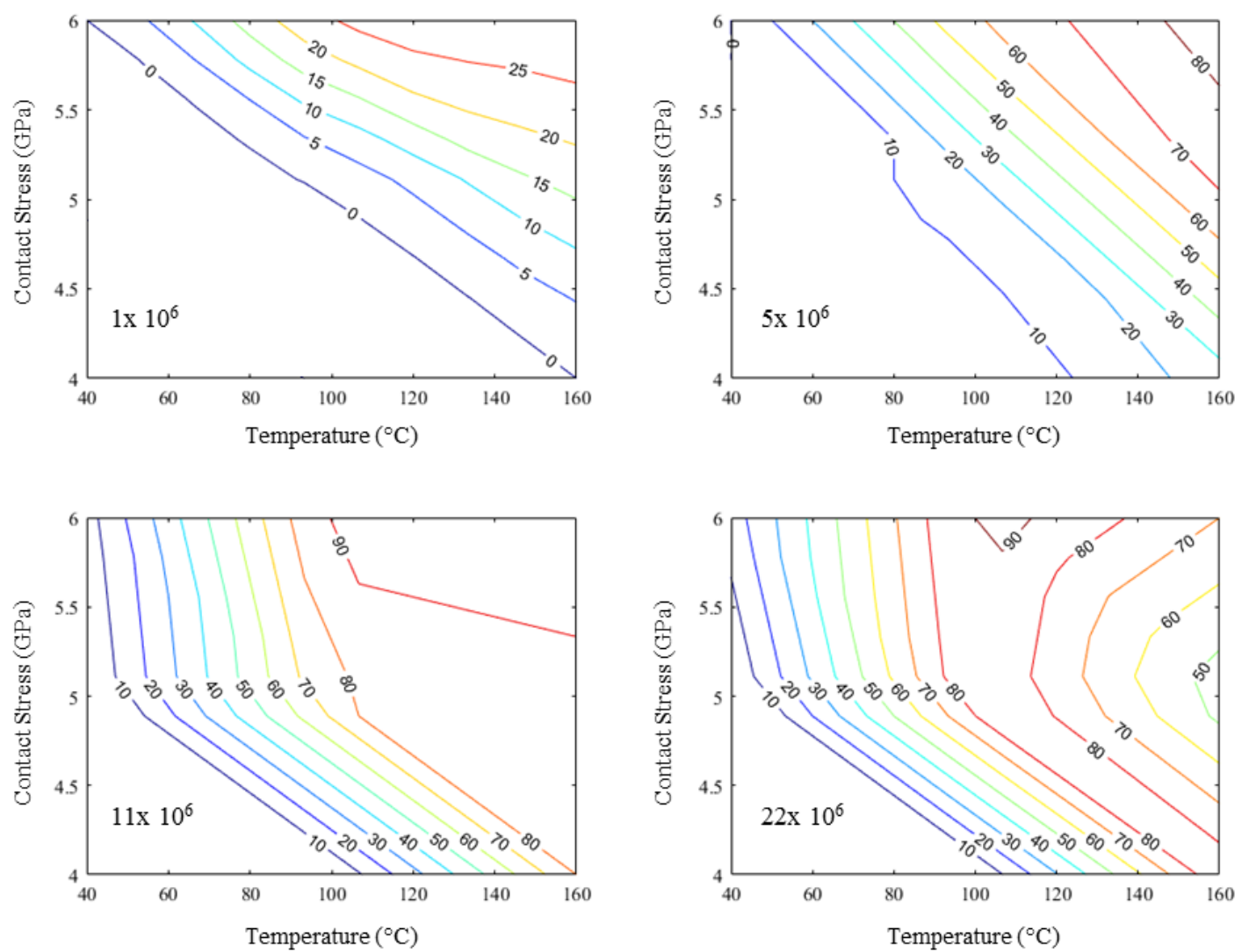

Figure 17. Evaluation of global maximum DER\% maps for temperature ' $\mathrm{T}$ ' and contact stress ' $\mathrm{P}_{\mathrm{o}}$ ' variation (a) Maps calculated for 1, 5, 11, 22 million cycles. (b), (c), (d) and (e) show the contour plots for respective stress cycles 
The analytical model for DERs states the carbide precipitation during strain-induced martensite decay where carbon in the martensitic phase leaves the matrix and reprecipitates at the pre-existed carbides. This postulate was presented by [24] and extended by [4] which states the thickening mechanism for carbides during DERs formation is driven by dislocation gliding and the carbon diffusion flux can be modelled by,

$$
\begin{gathered}
\mathrm{J}_{\mathrm{d}}=\frac{\mathrm{dr}}{\mathrm{dt}}\left(\mathrm{C}_{\mathrm{VP}}-\mathrm{C}_{\mathrm{V}}\right)=\frac{\Delta \gamma \mathrm{N}^{\prime}}{\mathrm{b}}\left[3\left(\frac{\pi}{2}\right)^{\frac{1}{3}}\left(\frac{\mathrm{AD}}{\mathrm{K}_{\mathrm{b}} \mathrm{TN}^{\prime}}\right)^{\frac{2}{3}} \mathrm{C}_{\mathrm{V}}\right] \\
\mathrm{C}_{\mathrm{V}}=\frac{L_{p} C_{V o}-2 r_{p} C_{V P}}{L_{p}-2 r_{p}}
\end{gathered}
$$

Where $\mathrm{J}_{\mathrm{d}}$ represents the diffusion flux of carbon which is driven by a constant plastic strain amplitude $\Delta \gamma$ provided that the remaining material parameters are known. Here $r_{p}$ represents the half-width of carbide plate, $\mathrm{C}_{\mathrm{VP}}$ and $\mathrm{C}_{\mathrm{V}}$ denotes carbon concentration in precipitates and matrix per unit volume, $\mathrm{A}$ denotes interaction energy, $\mathrm{b}$ denotes Burgers vector constants, $\mathrm{T}$ denotes temperature, $\mathrm{N}^{\prime}$ denotes rotational speed, $\mathrm{t}$ represents cycling time, $\mathrm{K}_{b}$ represents Boltzmann constant, $L_{p}$ denotes spacing between precipitates and $C_{V o}$ represents initial carbon concentration. The diffusivity of carbon (D) in the ferrite matrix can be calculated as $e^{-Q / R T}$. The depletion of carbon in the matrix is termed as DER\% and is defined as $\frac{C_{V o}-C_{V}}{C_{V o}}$. In order to measure the DER\%, equation (2) is substituted in equation (1), and solved for $r_{p}$. Once the $r_{p}$ is known, $C_{V}$ can be calculated from equation (2) and resulting DER\% can also be computed. The values of material parameters employed in numerical modelling are given in Table 3.

Figure $18(\mathrm{a}-\mathrm{c})$ represents the DER formation at $4 \mathrm{GPa}, 5 \mathrm{GPa}$ and $6 \mathrm{GPa}$ contact stress with $40^{\circ} \mathrm{C}, 100^{\circ} \mathrm{C}$ and $160^{\circ} \mathrm{C}$ temperature, predicted by the dislocation assisted DER numerical model and compared with experimentally measured DERs in current study. The numerically predicted DER\% at all given temperature and pressure were observed in the very stage of stress cycles in comparison with the given experimental data. It is evident that the dislocation gliding model over predicts the formation of DER under given condition. The dislocation gliding model considers strain-induced plasticity build-up as the primary cause for DER formation where the excess carbon in the solid solute migrates and causes microstructural alterations. The build-up of plastic strain and respective dislocation in the crystal lattice during RCF loading favours the continuous growth of DER width and size. Recall from figure 16 and figure 17 that the DER was influenced by the effects of temperature and contact stress where a significant difference in DER development and progression was observed with an increase in operating temperature. It can be deduced that the DER formation mechanism is a combined effect of thermal diffusion of carbon and dislocation gliding. It is important to incorporate the thermal effects during RCF loading condition in order to fully capture the true response of bearing material microstructural alterations. The shortcomings in previous numerical model can be further explained with the better understanding of the responsible stress component to drive the subsurface plasticity during RCF stress cycles. Dislocation gliding model assumes this subsurface plasticity to be caused by orthogonal shear stress where a constant $\Delta \gamma$ has been acquired either from the uniaxial compression testing or the torsional testing of bearing ball samples which cannot capture the true response of subsurface plasticity during RCF. Current research deliberately investigates the responsible stress component to be the evolved von Mises stress $S_{\text {evol }}$ acting below contact track with the superposition of residual stresses. It is suggested that a more realistic prognostic scheme can be built by considering all the reasonable factors driving RCF induced microstructural alterations i.e. thermal diffusion and cyclic plasticity 
during RCF. In addition, the reported DER\% maps can be employed as a guideline to accurately model the formation mechanism of visible microstructural alterations (DERs + WEBs) in bearing steel.

(a)

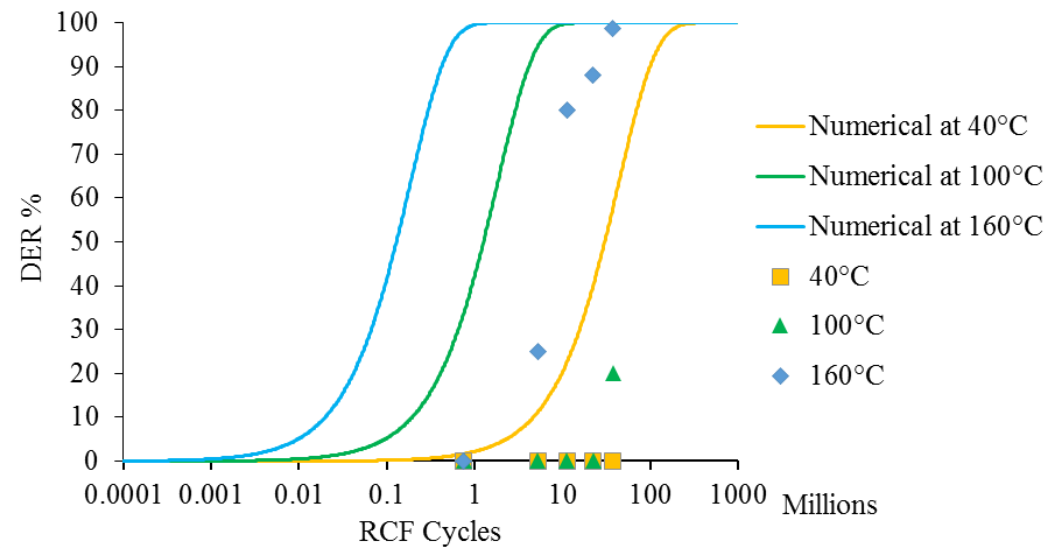

(b)

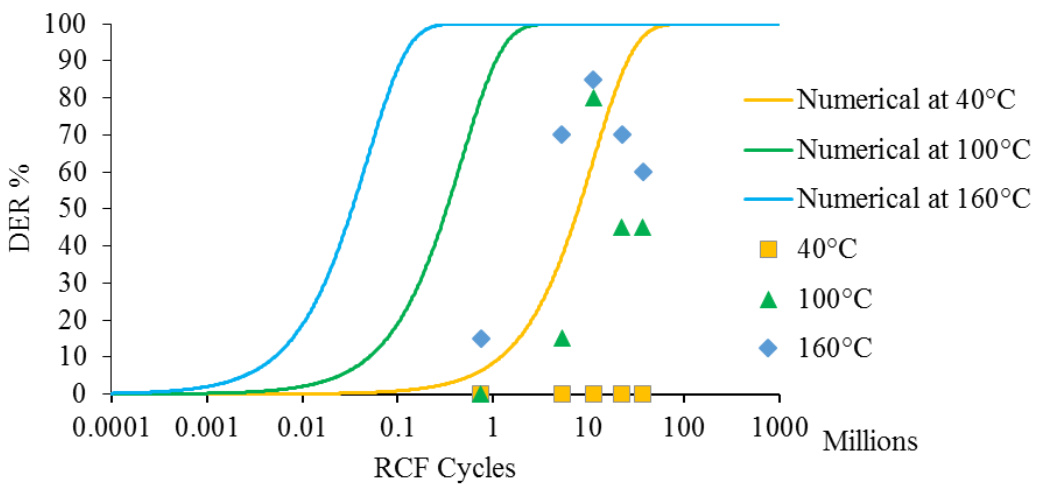

(c)

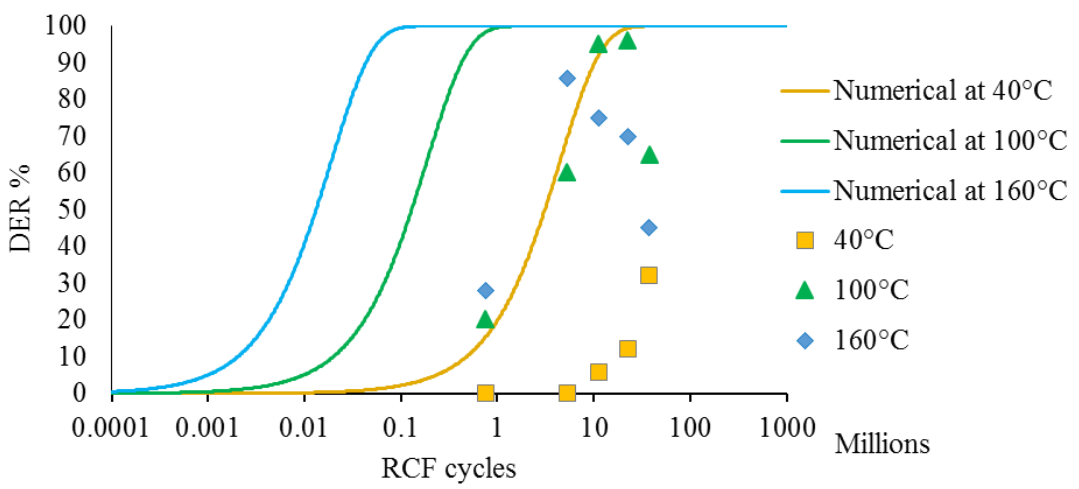

Figure 18. DER\% at (a) 4GPa, (b) 5GPa and (c) 6GPa contact stress with three different temperatures; as numerically predicted by dislocation gliding model [4] and current experimental data

Table 3. Material constants used in the numerical model

\begin{tabular}{cc}
\hline Constant & Value \\
\hline $\mathrm{A}$ & $3 \times 10^{-30} \mathrm{Nm}^{2}[25]$ \\
$\mathrm{b}$ & $0.2876 \mathrm{~nm}[4]$ \\
$\mathrm{D}$ & $\mathrm{D}_{\mathrm{o}} e^{-Q} / R T$ \\
$\mathrm{D}_{\mathrm{o}}$ & $6.2 \times 10^{-7} \mathrm{~m}^{2} \mathrm{~s}^{-1}[26]$ \\
$\mathrm{Q}$ & $80000 \mathrm{Jmol}^{-1} \mathrm{a} \mathrm{[26]}$ \\
$\mathrm{R}$ & $8.314 \mathrm{JK}^{-1} \mathrm{~mol}^{-1}$ \\
$\mathrm{~K}_{b}$ & $1.38 \times 10^{-23} \mathrm{~m}^{2} \mathrm{Kgs}^{-2} \mathrm{~K}^{-1}$ \\
$C_{V P}$ & $25.7955 \mathrm{at}^{2} / \mathrm{nm}^{3}[9]$
\end{tabular}




\begin{tabular}{cc}
$r_{p o}$ & $7 \mathrm{~nm} \mathrm{[4]}$ \\
$L_{p}$ & $209 \mathrm{~nm} \mathrm{[9]}$ \\
\hline
\end{tabular}

\section{Conclusions}

A rotary tribometer has been employed for rolling contact fatigue (RCF) testing of a standard AISI 52100 bearing steel balls. The experimentation of ball-on-ball point contact loading has been carried out at three different contact stress and operating temperature. The microstructure alterations have been evaluated by the help of subsurface microscopic investigations. This research concludes the subsequent key points;

1) Investigation of the contact track plasticity along with the subsequent microstructural alterations represents these changes (i.e. namely dark etching regions or DERs) to be associated with cyclic plasticity. With progressive stress cycles, DERs zone extends in each direction (towards core, surface and either side of contact track). The extent of DERs have been quantified in terms of rolling cycles, contact stress and operating temperatures. The continuous growth of DERs depends upon accumulation of plasticity which is governed by level of stress and operating temperature. Once the accumulation of plasticity is ceased, the DER growth tends to stop and represents a fully grown DER zone.

2) Image processing of RCF tested samples have revealed that the area fraction of DERs can be successfully quantified in terms of DER\%. At elevated temperatures, the development of DERs is accompanied by the formation of white etching bands (WEBs), which start to build up in a very early stage of rolling cycles. Furthermore, the DER results are presented as a combined function of temperature, stress and rolling cycles in terms of 3D DER\% Maps.

3) The quantitative comparison of DER profile with the subsurface stress components have revealed that the DERs can be governed by the evolved von Mises stresses with the superposition of compressive residual stresses, whereas the later progression and development of WEBs can be controlled by the maximum principal shear stresses.

4) The numerical prediction of DER formation from dislocation gliding model represent overprediction of DER formation when compared with the experimental data reported in current research. It is suggested that the dislocation gliding mechanism cannot alone predict the development of microstructural alterations where the effect of thermal diffusion and cyclic plasticity should be incorporated to model DERs/WEBs formation.

\section{Acknowledgement}

Authors would like to acknowledge Schaeffler Technologies AG \& Co, KG, Germany for their direct financial (grant ID: 10187) and in-kind support for conducting this research at Bournemouth University, United Kingdom.

\section{Appendix}

The spherical bodies under elastic contact are shown in figure A1. Maximum contact stress for ball-onball point contact can be estimated by classical Hertz theory [27]. 


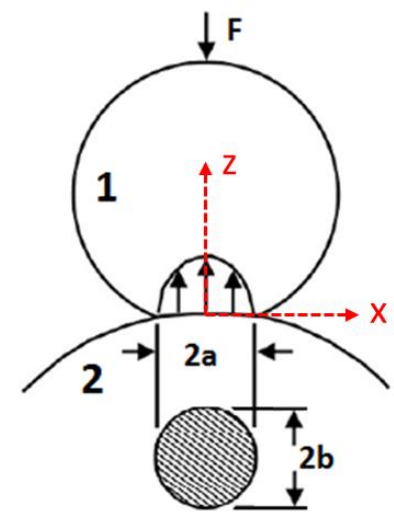

A 1. Spherical bodes under elastic contact

$$
\begin{gathered}
P_{o}=\frac{3 F}{2 \pi a^{2}} \\
\text { half width }=a=b=\sqrt[3]{\frac{3 F}{8}\left(\frac{\left(1-v_{1}^{2} / E_{1}\right)+\left(1-v_{2}^{2} / E_{2}\right)}{1 / d_{1}+1 / d_{2}}\right)} \\
\sigma_{x}=\sigma_{y}=-P_{o}\left[\left(1-\left|\frac{z}{a}\right| \tan ^{-1} \frac{1}{|Z / a|}\right)(1+v)-\frac{1}{2\left[\left(\frac{z}{a}\right)^{2}+1\right]}\right] \\
\sigma_{z}=-\frac{P_{o}}{1+\left(\frac{z}{a}\right)^{2}}
\end{gathered}
$$

Where $P_{o}$ represents maximum contact stress, $\mathrm{F}$ is applied normal load, $E \& v$ represents modulus of elasticity and Poisson's ratio respectively. Once the principal stresses $\sigma_{x}, \sigma_{y}, \sigma_{z}$ are known, the orthogonal shear stress $\tau_{o}$ can be calculated [27] with a maxima of $0.25 P_{o}$ acting $0.35 \mathrm{z} / \mathrm{a}$ (domain perpendicular to rolling direction) below contact point at a position of approximately $\pm 0.87 \mathrm{x} / \mathrm{a}$ ( $\mathrm{x}$ represents the horizontal domain in rolling direction). At centreline of contact track (i.e. $z=0$ ), the principal shear stress is represented as

$$
\begin{gathered}
\tau_{\max }=P_{0}\left[-\frac{3}{4} * \frac{1}{\left(\frac{\mathrm{z}}{\mathrm{a}}\right)^{2}+1}+\frac{1+\mathrm{v}}{2}\left[1-\frac{\mathrm{z}}{\mathrm{a}} \tan ^{-1} \frac{\mathrm{a}}{\mathrm{z}}\right]\right] \\
\mathrm{S}_{\mathrm{eq}}=\sqrt{\frac{1}{2}\left[\left(\sigma_{\mathrm{x}}-\sigma_{\mathrm{y}}\right)^{2}+\left(\sigma_{\mathrm{y}}-\sigma_{\mathrm{z}}\right)^{2}+\left(\sigma_{\mathrm{z}}-\sigma_{\mathrm{x}}\right)^{2}\right]}
\end{gathered}
$$

To calculate minimum film thickness $\left(\mathrm{h}_{\mathrm{min}}\right)$ and specific film thickness $(\lambda)$ for point contact load, the following equations can be used [28];

$$
\begin{gathered}
h_{\min }=3.63 \mathrm{R}^{\prime} \mathrm{U}^{0.68} \mathrm{G}^{0.49} \mathrm{~W}^{-0.073}\left(1-\mathrm{e}^{-0.68 \mathrm{k}}\right) \\
\frac{1}{\mathrm{E}^{\prime}}=\frac{1-\mathrm{v}_{1}^{2}}{\mathrm{E}_{1}}+\frac{1-\mathrm{v}_{2}^{2}}{\mathrm{E}_{2}}
\end{gathered}
$$




$$
\begin{gathered}
\frac{1}{\mathrm{R}^{\prime}}=\frac{1}{\mathrm{R}_{1}}+\frac{1}{\mathrm{R}_{2}} \\
\mathrm{U}=\frac{\eta_{\mathrm{o}} \mathrm{u}}{\mathrm{E}^{\prime} \mathrm{R}^{\prime}} \\
\mathrm{G}=\alpha \mathrm{E}^{\prime} \\
\mathrm{W}=\frac{\mathrm{F}}{\mathrm{E}^{\prime} \mathrm{R}^{\prime 2}} \\
\lambda=\frac{\mathrm{h}_{\mathrm{min}}}{\sqrt{2 \mathrm{r}_{\mathrm{rms}}{ }^{2}}}
\end{gathered}
$$

Here $\mathrm{k}, \eta_{\mathrm{o}}, \mathrm{u}, \mathrm{E}^{\prime}, \mathrm{R}^{\prime}, \alpha, \mathrm{F}, \mathrm{r}_{\mathrm{rms}}$ represents ellipticity ratio (b/a), atmospheric viscosity, mean speed, reduced elasticity, effective radius, viscosity-pressure coefficient, normal load and surface roughness respectively.

Rotational speed of spindle: $4051 \mathrm{rpm}$

Lubricant: ISO Vg-320, $320 \mathrm{cSt}(320 \mathrm{~mm} 2 / \mathrm{sec})$ at $40^{\circ} \mathrm{C}, 32.7 \mathrm{cSt}(32.7 \mathrm{~mm} 2 / \mathrm{sec})$ at $100^{\circ} \mathrm{C}$

Density: $0.86 \mathrm{~g} / \mathrm{ml}$ at $20^{\circ} \mathrm{C}$

Pressure viscosity coefficient, $\alpha=13 \mathrm{GPa}^{-1}$ at $40^{\circ} \mathrm{C}, 9 \mathrm{GPa}$ at $100^{\circ} \mathrm{C}$ [29]

Modulus of elasticity, $\mathrm{E}=210 \mathrm{GPa}$

$\mathrm{v}=0.3$

Measured Surface roughness of samples $=r_{r m s}=0.0109 \pm 0.002 \mu \mathrm{m}$

Table 4. Calculations for lubrication regime

\begin{tabular}{rrrr}
\hline $\begin{array}{r}\text { Maximum Contact Pressure } \\
(\mathrm{GPa})\end{array}$ & $\begin{array}{r}\text { Temperature } \\
\left({ }^{\circ} \mathrm{C}\right)\end{array}$ & $\begin{array}{r}\text { Minimum film thickness } \\
(\mu \mathrm{m})\end{array}$ & $\begin{array}{r}\text { Specific film thickness } \\
(\mu \mathrm{m})\end{array}$ \\
\hline 6 & 40 & 0.42 & 27.24632 \\
6 & 100 & 0.06 & 3.892331 \\
6 & 160 & 0.019 & 1.232571 \\
\hline
\end{tabular}

The specific film thickness obtained for $40^{\circ} \mathrm{C}$ and $100^{\circ} \mathrm{C}$ temperature shows a full fluid film lubrication between upper ball and lower balls in contact, whereas at a temperature as high as $160^{\circ} \mathrm{C}$, elastohydrodynamic (EHL) to mixed lubrication regime is expected where asperities can come in contact and cause initial plastic deformation of contact track along with minimal wear. 


\section{References}

1. Arakere, N.K., Gigacycle rolling contact fatigue of bearing steels: A review. International Journal of Fatigue, 2016. 93: p. 238-249.

2. Bush, J., W. Grube, and G. Robinson, Microstructural and residual stress changes in hardened steel due to rolling contact. Transactions of the ASM, 1961. 54: p. 390-412.

3. Swahn, H., P. Becker, and O. Vingsbo, Martensite decay during rolling contact fatigue in ball bearings. Metallurgical and Materials Transactions A, 1976. 7(8): p. 1099-1110.

4. $\quad \mathrm{Fu}, \mathrm{H}$., et al., Strain-induced martensite decay in bearing steels under rolling contact fatigue: modelling and atomic-scale characterisation. Acta Materialia, 2017. 139: p. 163-173.

5. Bhattacharyya, A., G. Subhash, and N. Arakere, Evolution of subsurface plastic zone due to rolling contact fatigue of M-50 NiL case hardened bearing steel. International Journal of Fatigue, 2014. 59: p. 102-113.

6. Voskamp, A., et al., Gradual changes in residual stress and microstructure during contact fatigue in ball bearings. Metals Technology, 1980. 7(1): p. 14-21.

7. $\quad \mathrm{Fu}, \mathrm{H}$. and P.E.J.A.M. Rivera-Díaz-del-Castillo, $A$ unified theory for microstructural alterations in bearing steels under rolling contact fatigue. 2018. 155: p. 43-55.

8. Šmelova, V., et al., Electron microscopy investigations of microstructural alterations due to classical Rolling Contact Fatigue (RCF) in martensitic AISI 52100 bearing steel. International Journal of Fatigue, 2017. 98: p. 142-154.

9. Kang, J.-H., et al., Modelling dislocation assisted tempering during rolling contact fatigue in bearing steels. International Journal of Fatigue, 2015. 75: p. 115-125.

10. Pernach, M. and M. Pietrzyk, Numerical solution of the diffusion equation with moving boundary applied to modelling of the austenite-ferrite phase transformation. Computational Materials Science, 2008. 44(2): p. 783-791.

11. Warhadpande, A., F. Sadeghi, and R.D. Evans, Microstructural Alterations in Bearing Steels under Rolling Contact Fatigue: Part 2-Diffusion-Based Modeling Approach. Tribology Transactions, 2014. 57(1): p. 66-76.

12. Mitamura, N., H. Hidaka, and S. Takaki. Microstructural development in bearing steel during rolling contact fatigue. in Materials science forum. 2007. Trans Tech Publ.

13. Voskamp, A., Material response to rolling contact loading. ASME, Transactions, Journal of Tribology(ISSN 0742-4787), 1985. 107: p. 359-364.

14. Rico, J.F., A.H. Battez, and D.G.J.T.I. Cuervo, Rolling contact fatigue in lubricated contacts. Tribology International, 2003. 36(1): p. 35-40.

15. Kang, J. and M. Hadfield, Comparison of four-ball and five-ball rolling contact fatigue tests on lubricated Si3N4/steel contact. Materials \& Design, 2003. 24(8): p. 595-604.

16. Kang, J.H., B. Hosseinkhani, and P.E.J. Rivera-Díaz-del-Castillo, Rolling contact fatigue in bearings: multiscale overview. Materials Science and Technology, 2012. 28(1): p. 44-49.

17. Radhakrishnan, V. and S. Ramanathan, Plastic deformation in rolling contact. Wear, 1975. 32(2): p. 211-221.

18. Golmohammadi, Z., A. Walvekar, and F. Sadeghi, A 3D efficient finite element model to simulate rolling contact fatigue under high loading conditions. Tribology International, 2018.

19. El Laithy, M., et al., Re-investigation of dark etching regions and white etching bands in SAE 52100 bearing steel due to rolling contact fatigue. International Journal of Fatigue, 2020: p. 105591.

20. Zwirlein, $\mathrm{O}$. and $\mathrm{H}$. Schlicht, Rolling contact fatigue mechanisms-accelerated testing versus field performance, in Rolling Contact Fatigue Testing of Bearing Steels. 1982, ASTM International.

21. Johnson, K., Formation of shear bands in ball-bearing races. 1988: University of Cambridge Department of Engineering.

22. Fu, H., Rivera-Díaz-del-Castillo, Pedro EJ, Evolution of White Etching Bands in 100Cr6 Bearing Steel under Rolling Contact-Fatigue. Metals, 2019. 9(5): p. 491. 
23. Barrow, A., J.-H. Kang, and P. Rivera-Díaz-del-Castillo, The $\epsilon \rightarrow \eta \rightarrow \vartheta$ transition in $100 \mathrm{Cr} 6$ and its effect on mechanical properties. Acta materialia, 2012. 60(6-7): p. 2805-2815.

24. Kang, J.-H., et al., Modelling dislocation assisted tempering during rolling contact fatigue in bearing steels. 2015. 75: p. 115-125.

25. Cottrell, A.H. and B. Bilby, Dislocation theory of yielding and strain ageing of iron. Proceedings of the Physical Society. Section A, 1949. 62(1): p. 49.

26. Bhadeshia, H. and R. Honeycombe, Steels: microstructure and properties. 2017: ButterworthHeinemann.

27. Johnson, K.L. and K.L. Johnson, Contact mechanics. 1987: Cambridge university press.

28. Hamrock, B.J. and D. Dowson, Isothermal elastohydrodynamic lubrication of point contacts: part III-fully flooded results. 1977.

29. Vengudusamy, B., C. Enekes, and R. Spallek, EHD friction properties of ISO VG 320 gear oils with smooth and rough surfaces. Friction, 2020. 8(1): p. 164-181. 